\title{
Increasing Competition and the Winner's Curse: Evidence from Procurement
}

\author{
HAN HONG \\ Princeton University \\ and \\ MATTHEW SHUM \\ Johns Hopkins University
}

First version received February 2000; final version accepted December 2001 (Eds.)

\begin{abstract}
We assess empirically the effects of the winner's curse which, in common-value auctions, counsels more conservative bidding as the number of competitors increases. First, we construct an econometric model of an auction in which bidders' preferences have both common- and private-value components, and propose a new monotone quantile approach which facilitates estimation of this model. Second, we estimate the model using bids from procurement auctions held by the State of New Jersey. For a large subset of these auctions, we find that median procurement costs rise as competition intensifies. In this setting, then, asymmetric information overturns the common economic wisdom that more competition is always desirable.
\end{abstract}

\section{INTRODUCTION}

How do increases in competition affect equilibrium bidding at auctions? According to the Walrasian analogy of markets as auctions, an increase in the number of bidders should encourage more aggressive bidding so that, in the limit, as the number of bidders becomes arbitrarily large, the imperfectly competitive auction setting approaches the efficient perfectly competitive outcome.

While this is true within the independent private-values paradigm, it may not be true at auctions with affiliated signals, an important subset of which are common-value (hereafter CV) auctions in which the competing bidders are differentially (but incompletely) informed about the value of the object which they are trying to win. A distinctive feature of common-value auctions is the winner's curse, an adverse-selection problem which arises because the winner tends to be the bidder with the most overly optimistic information (or "signal") concerning the object's value. Bidding naively based simply on one's information would lead to negative expected profits so that, in equilibrium, a rational bidder internalizes the winner's curse by bidding less aggressively. ${ }^{1}$

In common-value settings, however, an increase in the number of bidders has two counteracting effects on equilibrium bidding behaviour. First, the increased competition generally leads to more aggressive bidding, as each potential bidder tries to maintain her chances of winning against more rivals: we call this the competitive effect. Second, the winner's curse

1. More precisely, in the procurement (low-bid) setting, even if any bidder's signal $x$ is an unbiased estimate of the unknown (but common) project cost $c$ (i.e. $E(x)=c$ ), conditional on winning the signal is a downwardly biased estimate of $c$ (i.e. $E(x \mid$ win $)<c$ ). This implies that if a bidder were to naively bid her unbiased signal $x$, her expected profits $E(x-c \mid$ win $)$ would be negative. 
becomes more severe as the number of potential bidders increases, and rational bidders will bid less aggressively in response: we call this the winner's curse effect. If the winner's curse effect is large enough, prices could actually rise as the number of competitors increases. Recently, Bulow and Klemperer (1999), Krishna and Morgan (1997), and Bordley and Harstad (1996) have pointed out this possibility; as these authors note, the winner's curse provides a prominent example where asymmetric information can overturn the common economic wisdom that more competition is always desirable. Recently, Pinkse and Tan (2000) (hereafter PT) have shown that this decrease in bidding aggressiveness as competition increases can occur generally in affiliated-values first-price auctions so that, while the winner's curse does not arise in privatevalues settings, an affiliation effect in affiliated private-values models also leads to less aggressive equilibrium bidding as competition increases, similar to the effect of the winner's curse in common-value auctions. ${ }^{2}$

In this paper, we consider the empirical importance of these considerations using bid data from construction procurement auctions held by the New Jersey Department of Transportation (NJDOT) in the years 1989-1997. We address two questions in turn. First, we examine the importance of common-value components in bidders' preferences. Second, provided we find some evidence of common values, we investigate how the winner's curse affects equilibrium bidding. We do this by quantifying two comparative statics which have been the focus of the theoretical work on common-value auctions. First, does an increase in the number of competitors lead a given bidder to bid more or less aggressively, in equilibrium? Theoretical examples in Smiley (1979) and Matthews (1984) have shown that the result often depends on both the parametric assumptions on the information structure as well as the specific values of the parameters, and we measure the effects using the parameter estimates for our model of equilibrium bidding. Second, and more important for policy purposes, does the winning bid rise or fall as competition increases? Previous theoretical work (e.g. Wilson (1977), Milgrom (1979)) have studied convergence of the winning bid in large CV auctions. In contrast, we measure these effects for the (often modest) range of bidders which we observe in real-world auctions. To our knowledge, we are the first to address these issues empirically.

The procurement setting is particularly pertinent for the issues raised above. Although exact figures are difficult to obtain, McAfee and McMillan (1987, p. 3) claim that "the national, regional, and local governments in a typical modern market economy together spend between one-quarter and one-third of national income on goods and services [...]; of this amount, perhaps one-half [...] is paid by governments to firms". Many of these payments are for contract work awarded via low-bid auctions identical to those considered here, so that there appear to be important efficiency and revenue lessons to be learned from the results.

Our results show that different types of contracts differ substantially in the degree that private- and/or common-value components are important. We find that both common-value and private-value components are important in auctions for highway-work and bridge-repair contracts, while more homogeneous road paving contracts are predominantly private-value auctions. These results indicate that the winner's curse effect is particularly strong in highwaywork auctions: simulated bid functions show that the median bidder's equilibrium bid increases from about $\$ 0.2$ million with 2 bidders to above $\$ 0.6$ million with 10 bidders. $^{3}$ Moreover, winning bid simulations indicate that the average procurement cost is strictly increasing in the

2. While we focus on the effects of the winner's curse in this paper, we note that the PT result implies that winner's curse-like effects can arise even in private-values settings, as long as signals are affiliated. One advantage of our structural estimation approach is that we can explicitly test whether any observed decrease in bidding aggressiveness as competition increases is due to winner's curse effects, or to PT's "affiliation effect".

3. Furthermore, simulations also show that these effects arise from the winner's curse effect, not from the affiliation effect described by PT. 
number of bidders as competition intensifies: for example, the average costs rise about $15 \%$, as the number of bidders increases from three to six. For these auctions, the optimal number of participants or potential bidders (which would minimize expected procurement costs) would be three. Clearly, cases exist where the "law of demand" is violated: an increase in competition leads to higher procurement costs.

In the next section we describe the model of equilibrium bidding which we employ in our work. In Section 3, we introduce our data on New Jersey transportation department procurement auctions, and discuss institutional features which affect our model specification, which we introduce in Section 4. Section 5 contains the empirical results, and in Section 6 we discuss the policy implications of our results. Section 7 concludes.

\section{EQUILIBRIUM BIDDING AT LOW-PRICE PROCUREMENT AUCTIONS}

In our empirical work, we employ a structural approach which allows us to recover bidders' equilibrium strategies. ${ }^{4}$ We build on the previous literature by considering a model where bidders' valuations have both private- and common-value components. Such a model seems especially warranted for procurement settings, where uncertainty about future input prices could drive common values but differences in input efficiency across firms could drive private values. ${ }^{5}$

To our knowledge, this paper is among the first to investigate structural estimation of an equilibrium bidding model where bidders' valuations have both private- and common-value components. Previously, Laffont and Vuong (1996) argued that it is impossible to distinguish nonparametrically a common value model from a private value model. Subsequently, others have argued that while it is not possible to identify nonparametrically the joint distribution of the common-value component and bidders' signals, it is possible to test nonparametrically between common- and private-value paradigms. Hendricks et al. (2000) formulated nonparametric tests by exploiting the presence of a binding reserve price, and in ongoing work (Haile, Hong and Shum, 2000), we propose tests which exploit exogenous variation in the number of potential bidders. In this paper, however, we adopt a parametric approach to recover the joint distribution of bidders' valuations and signals which characterize the information structure.

Next, we briefly describe equilibrium bidding behaviour in single-unit, low-price procurement auctions. ${ }^{6}$ An auction has $n$ risk-neutral contractors (indexed $i=1, \ldots, n$ ), each of whom has a cost $c_{i}$ associated with completing the project, and receives a private signal $x_{i}$ about $c_{i}$. Contractor $i$ observes only $x_{i}$ prior to the beginning of the auction, but not any of the costs $\left(c_{j}\right.$, for $\left.j=1, \ldots, n\right)$, or any of her rivals' signals $\left(x_{j}\right.$, for $\left.j \neq i\right)$.

The contractors' costs and private signals are assumed to be distributed according to the distribution function $\tilde{F}\left(c_{1}, \ldots, c_{n}, x_{1}, \ldots, x_{n} ; \theta\right)$ parametrized by the vector of parameters $\theta$,

4. The seminal empirical auction papers in the structural vein are by Paarsch (1992) and Laffont, Ossard and Vuong (1995). Most recently, important progress has been made in the structural estimation of private-value auction models (see Paarsch (1997), Bajari (1998), Guerre, Perrigne and Vuong (2000), Li, Perrigne and Vuong (2000), Deltas and Chakraborty (1997)).

5. In previous work (Hong and Shum, 2000), we have empirically implemented an equilibrium ascendingprice auction model also allowing for both private and common values. Previously, Bajari (1998) and Jofre-Bonet and Pesendorfer (1999) have modelled procurement auctions in a private-values framework. Recently, Hendricks, Pinkse and Porter (2000) and Bajari and Hortacsu (1999) have also considered common-value models, but they consider pure common-value (i.e. "mineral rights") models of competitive bidding. Our model has both common and private values.

In a previous study of procurement auctions, Thiel (1988) concluded that observed bids do indeed reflect winner's curse considerations, but we take the analysis one step further by showing what this implies about equilibrium bids and, more important, equilibrium procurement costs.

6. The assumption of rational equilibrium bidding which characterizes our approach is potentially at odds with findings in the experimental literature (cf. Kagel and Levin (1986)), which find that bidders only learn to internalize the winner's curse (i.e. bid "rationally") through experience. In the procurement setting, however, the bidders are by and large experienced firms, so we feel our assumption of rational bidding is justified. 
which are the parameters of interest in the estimation process. As we describe in the next section, we consider a specification which allows both common-value and private-value components in bidders' cost functions. ${ }^{7}$

The low-price auction proceeds as follows: observing $x_{i}$, contractor $i$ chooses a bid $b_{i}$ to maximize his expected payoff, given the other contractors' equilibrium behaviour:

$$
b_{i}=\operatorname{argmax}_{b} E_{x_{j}, j \neq i} E_{c_{i} \mid x_{1}, \ldots, x_{n}}\left[\left(b-c_{i}\right) \mathbf{1}\left(x_{j} \geq s_{j, n}^{-1}(b), j \neq i\right) \mid x_{i}\right]
$$

where $s_{i, n}(\cdot), i=1, \ldots, n$ denotes the equilibrium bidding strategy (or bid function) for contractor $i$ in a $n$-bidder auction.

We assume that contractors are symmetric, in the sense that the joint distribution $\tilde{F}$ is exchangeable with respect to the indexes $1, \ldots, n$. As is standard, we assume that the random variables $\left(c_{1}, \ldots, c_{n}, x_{1}, \ldots, x_{n}\right)$ are affiliated. ${ }^{8}$ Given these assumptions, there is a unique pure-strategy Bayesian-Nash equilibrium in which each contractor bids according to identical, monotonically increasing strategies; i.e. $s_{j, n}(\cdot) \equiv s_{n}(\cdot), \forall j .{ }^{9}$

The first-order condition of this maximization problem is (cf. Milgrom and Weber (1982, p. 1107))

$$
s_{n}\left(x_{i}\right)=\frac{s_{n}^{\prime}\left(x_{i}\right)\left[1-F_{-i, n}\left(x_{i} \mid x_{i}\right)\right]}{f_{-i, n}\left(x_{i} \mid x_{i}\right)}+v_{n}\left(x_{i}, x_{i}\right),
$$

a differential equation which defines the equilibrium bidding strategy $s_{n}\left(x_{i}\right)$. In this equation, $v_{n}(\cdot, \cdot)$ is the conditional expectation

$$
v_{n}(x, y)=E\left[c_{i} \mid x_{i}=x, \min _{j \in[1, n] ; j \neq i} x_{j}=y\right],
$$

where the expectation is taken over the posterior distribution of $c_{i}$ conditional on the joint event $\left(x_{i}=x, \min _{j \in[1, n] ; j \neq i} x_{j}=y\right) . f_{-i, n}(\cdot \mid \cdot)$ (resp. $\left.F_{-i, n}(\cdot \mid \cdot)\right)$ denotes the conditional density (resp. CDF) of $\min _{j \neq i} x_{j}$ conditional on $x_{i}$. After integrating out this differential equation, the equilibrium bid function can be expressed as (cf. Milgrom and Weber (1982, Theorem 14))

$$
s_{n}\left(x_{i}\right)=v_{n}\left(x_{i}, x_{i}\right)+\int_{x_{i}}^{\bar{x}}\left\{\exp \left[-\int_{x_{i}}^{\alpha} \frac{f_{-i, n}(s \mid s)}{1-F_{-i, n}(s \mid s)} d s\right]\right\} v_{n}^{\prime}(\alpha, \alpha) d \alpha
$$

where the $n$ subscript emphasizes that for a given $x_{i}$, the equilibrium bid $s_{n}\left(x_{i}\right)$ varies for different $n$.

\subsection{Winner's curse and competitive effects}

The competitive and winner's curse effects alluded to earlier are distinguishable in equation (1) above. From this equation we see that an equilibrium bid $b_{i}=s\left(x_{i}\right)$ is governed by two important components: (1) the $\frac{s^{\prime}\left(x_{i}\right)\left[1-F_{-i}\left(x_{i} \mid x_{i}\right)\right]}{f_{-i}\left(x_{i} \mid x_{i}\right)}$ term and (2) the $v_{n}\left(x_{i}, x_{i}\right)$ term. Given our affiliation assumptions, an increase in $n$ will increase the second term $v_{n}\left(x_{i}, x_{i}\right)$, holding $x_{i}$

7. In the pure private-value paradigm, $c_{i}=x_{i} \forall i$ (i.e. each bidder knows his true valuation for the object) while in the pure common-value paradigm, $c_{i}=c, \forall i$ (i.e. the value of the object is the same to all bidders, but none of the bidders knows the true value of the object; here the individual $x_{i}$ 's are noisy signals of the true but unknown $x$ ).

8. (Cf. Milgrom and Weber (1982).) Affiliation roughly implies that large values for some of the variables make the other variables more likely to be large than small. Given two $n$-vectors $\mathbf{X}_{1}$ and $\mathbf{X}_{2}$ which are i.i.d. realizations from $F$, let $\overline{\mathbf{X}}$ denote the componentwise maximum of $\mathbf{X}_{1}$ and $\mathbf{X}_{2}$, and $\underline{\mathbf{X}}$ the component-wise minimum. Affiliation means that the likelihood of $(\overline{\mathbf{X}}, \underline{\mathbf{X}})$ is at least as high as that of $\left(\mathbf{X}_{1}, \mathbf{X}_{2}\right)$.

9. Symmetry and monotonicity imply that $b_{i}>b_{j} \Leftrightarrow s_{n}\left(x_{i}\right)>s_{n}\left(x_{j}\right) \Leftrightarrow x_{i}>x_{j}$. Analogously, the event that bidder $i$ wins can be simplified: $\mathbf{1}\left(x_{j} \geq s_{j, n}^{-1}\left(b_{i}\right), j \neq i\right)=\mathbf{1}\left(x_{j} \geq s_{n}^{-1}\left(b_{i}\right), j \neq i\right)=\mathbf{1}\left(\min _{j \neq i} x_{j} \geq x_{i}\right)$, since $x_{i}=s_{n}^{-1}\left(b_{i}\right)$ in equilibrium. 
TABLE 1

Breakdown of auctions by job type

\begin{tabular}{llcccrr}
\hline & Worktype & \# Auctions & $\begin{array}{c}\text { Avg. } \\
\text { winning bid } \\
(1989 \$ ; \text { mils })\end{array}$ & $\begin{array}{c}\text { Std. dev., } \\
\text { winning bid }\end{array}$ & $\begin{array}{c}\text { Total } \\
\text { bidders }\end{array}$ & $\begin{array}{c}\text { Total } \\
\text { winners }\end{array}$ \\
\hline A & General highway & 423 & 4.97 & 9.61 & 274 & 121 \\
B & Bridge construc./repair & 194 & 1.48 & 1.82 & 171 & 74 \\
C & Grading \& paving & 150 & 0.97 & 1.11 & 109 & 33 \\
\hline
\end{tabular}

fixed (cf. Milgrom (1982, Section 6)). ${ }^{10}$ This is the winner's curse effect. On the other hand, an increase in $n$ will generally have an ambiguous effect on the first term. On the one hand, the $\left[1-F_{-i}\left(x_{i} \mid x_{i}\right)\right]$ portion of the numerator of the first term is essentially the probability of winning the low-bid auction for a given signal $x_{i}$, and this probability shrinks to zero as $n$ increases. Thus for large $n$, the first term should be decreasing in $n$ : we call this the competitive effect. ${ }^{11}$

At independent private-value auctions, the winner's curse effect is absent so, ceteris paribus, we should expect the bids to decrease as the number of participants increases, due solely to the competitive effect. At auctions where bidders' costs have both common-value and private-value components (as is the case in the model we employ), it is unclear which effect(s) will dominate: this is an empirical question, which can only be answered once one obtains estimates of the structural parameters in bidders' preferences.

\section{NEW JERSEY DEPARTMENT OF TRANSPORTATION CONSTRUCTION SERVICES PROCUREMENT AUCTIONS}

In order to examine empirically the questions we have raised, we collected a data set of bids submitted in procurement contract auctions conducted by the NJDOT in the years 1989-1997. Over this period, the NJDOT conducted 1018 low-price, sealed-bid auctions of contracts to procure various services. For our empirical work, we focus on auctions for three types of jobs: highway work (worktype A in what follows), bridge construction and maintenance (worktype B), and road paving (worktype $\mathrm{C}$ ), which together account for over half of the contracts auctioned during the sample period. (See Table 1 for summary statistics for these auctions.)

Clearly, the variation in the average winning bid across types of contracts indicates that the jobs defined in these contracts are markedly different. For that reason, we estimate separate parameters for each type of contract in our empirical work.

Summary statistics. Table 2 presents statistics on the observed bids, broken down according to the number of actual bidders who participated in the auction. Most auctions have between 3 and 7 bidders, and the NJDOT did not impose an explicit reserve price. ${ }^{12}$ Importantly, there is a generally increasing (but by no means monotonically so) trend between number of bidders and both submitted and winning bids. For example, the average bid in the worktype A

10. This is only true for common-value models, but not for private-value models. In ongoing work (Haile et al., 2000), we are using this insight as the basis of a formal test for the presence of common-value components, based upon recent developments by Guerre et al. (2000) and Hendricks et al. (2000) in the nonparametric estimation of structural auction models.

11. PT (cf. Lemma 1) note that for high-bid first-price auctions, in the affiliated private-values framework, for some intermediate values of $n$ and some signals $x_{i}$, the ratio $\left[f_{-i, n}\left(x_{i} \mid x_{i}\right) / F_{-i, n}\left(x_{i} \mid x_{i}\right)\right]$ could be decreasing in $n$, thus exacerbating the winner's curse effect.

12. We return to the issue of an implicit reserve price later, when we consider the possibility that the actual number of bidders observed in these auctions may not correspond to the potential number of bidders. 
TABLE 2

Summary statistics on bids

\begin{tabular}{|c|c|c|c|c|c|c|}
\hline Worktype & $\begin{array}{l}\text { Number } \\
\text { of bidders }\end{array}$ & \# Auctions & $\begin{array}{c}\text { Average } \\
\text { bid (1989\$; mils) }\end{array}$ & Std. dev. & $\begin{array}{c}\text { Median } \\
\text { bid (1989\$; mils) }\end{array}$ & $\begin{array}{c}\text { Average } \\
\text { winning bid }\end{array}$ \\
\hline A & 2 & 12 & $5 \cdot 894$ & 14.954 & 1.482 & $5 \cdot 601$ \\
\hline A & 3 & 31 & 1.692 & $2 \cdot 000$ & $1 \cdot 042$ & $1 \cdot 520$ \\
\hline A & 4 & 46 & $1 \cdot 843$ & 1.919 & $1 \cdot 124$ & 1.605 \\
\hline A & 5 & 51 & $3 \cdot 380$ & $5 \cdot 223$ & $1 \cdot 204$ & $3 \cdot 015$ \\
\hline A & 6 & 58 & $4 \cdot 513$ & $8 \cdot 310$ & $1 \cdot 369$ & $3 \cdot 982$ \\
\hline A & 7 & 46 & 4.435 & 9.751 & 1.406 & $3 \cdot 526$ \\
\hline A & 8 & 40 & $6 \cdot 365$ & $12 \cdot 567$ & $3 \cdot 000$ & $5 \cdot 229$ \\
\hline A & 9 & 39 & 8.658 & $15 \cdot 438$ & $4 \cdot 016$ & $6 \cdot 640$ \\
\hline A & 10 & 22 & $10 \cdot 612$ & $12 \cdot 828$ & 4.745 & $9 \cdot 256$ \\
\hline A & 11 & 20 & $15 \cdot 087$ & $30 \cdot 432$ & $2 \cdot 951$ & $11 \cdot 471$ \\
\hline A & 12 & 17 & $11 \cdot 704$ & $10 \cdot 935$ & $7 \cdot 739$ & $10 \cdot 263$ \\
\hline A & 13 & 12 & $10 \cdot 652$ & 14.879 & 3.767 & 8.984 \\
\hline A & 14 & 8 & $10 \cdot 523$ & $12 \cdot 264$ & $4 \cdot 229$ & $9 \cdot 350$ \\
\hline A & 15 & 8 & $9 \cdot 274$ & $10 \cdot 338$ & $4 \cdot 885$ & $8 \cdot 274$ \\
\hline A & 16 & 3 & $2 \cdot 506$ & $1 \cdot 053$ & $2 \cdot 477$ & $1 \cdot 544$ \\
\hline A & 17 & 4 & 9.999 & $5 \cdot 029$ & 9.830 & $8 \cdot 583$ \\
\hline B & 2 & 12 & $1 \cdot 265$ & 0.651 & $1 \cdot 171$ & $1 \cdot 167$ \\
\hline B & 3 & 7 & 1.577 & $1 \cdot 244$ & $1 \cdot 368$ & 1.432 \\
\hline B & 4 & 24 & 1.672 & 0.495 & $1 \cdot 193$ & $1 \cdot 386$ \\
\hline B & 5 & 12 & 1.049 & 0.730 & 0.999 & 0.819 \\
\hline B & 6 & 23 & 1.566 & 1.265 & $1 \cdot 175$ & 1.286 \\
\hline B & 7 & 23 & $1 \cdot 278$ & $1 \cdot 120$ & 0.968 & 1.001 \\
\hline B & 8 & 16 & $2 \cdot 644$ & 3.496 & 1.064 & $2 \cdot 241$ \\
\hline B & 9 & 19 & 1.755 & 1.439 & 1.266 & $1 \cdot 349$ \\
\hline B & 10 & 14 & 1.480 & $1 \cdot 245$ & 1.065 & $1 \cdot 141$ \\
\hline B & 11 & 7 & $1 \cdot 149$ & 0.811 & 1.010 & 0.888 \\
\hline B & 12 & 10 & 1.932 & 1.899 & 1.019 & $1 \cdot 398$ \\
\hline B & 13 & 13 & $2 \cdot 261$ & 2.457 & 1.063 & 1.869 \\
\hline B & 14 & 5 & 1.784 & 1.496 & 0.728 & 1.462 \\
\hline B & 15 & 3 & 8.472 & $6 \cdot 032$ & $6 \cdot 953$ & $6 \cdot 873$ \\
\hline B & 16 & 5 & 2.658 & $2 \cdot 816$ & $1 \cdot 254$ & 1.952 \\
\hline B & 17 & 6 & 3.056 & 3.825 & $1 \cdot 352$ & $2 \cdot 415$ \\
\hline $\mathrm{C}$ & 2 & 9 & 0.737 & 0.418 & 0.679 & 0.664 \\
\hline $\mathrm{C}$ & 3 & 21 & 0.629 & $0 \cdot 308$ & 0.650 & 0.546 \\
\hline $\mathrm{C}$ & 4 & 23 & 1.086 & 0.624 & 0.968 & 0.910 \\
\hline $\mathrm{C}$ & 5 & 34 & 1.566 & $2 \cdot 266$ & 1.068 & $1 \cdot 347$ \\
\hline $\mathrm{C}$ & 6 & 27 & 0.826 & 0.674 & 0.543 & 0.705 \\
\hline $\mathrm{C}$ & 7 & 19 & 1.469 & $1 \cdot 011$ & $1 \cdot 320$ & $1 \cdot 273$ \\
\hline $\mathrm{C}$ & 8 & 8 & 0.961 & 0.608 & 0.963 & 0.789 \\
\hline $\mathrm{C}$ & 9 & 4 & 2.424 & 0.939 & $2 \cdot 045$ & 2.059 \\
\hline $\mathrm{C}$ & 10 & 5 & 1.087 & $0 \cdot 518$ & 0.951 & 0.955 \\
\hline $\mathrm{C}$ & 11 & 4 & $1 \cdot 164$ & 0.801 & 1.056 & 0.844 \\
\hline $\mathrm{C}$ & 12 & 1 & $1 \cdot 231$ & 0.098 & $1 \cdot 221$ & $1 \cdot 105$ \\
\hline $\mathrm{C}$ & 14 & 1 & $0 \cdot 152$ & 0.057 & 0.138 & 0.094 \\
\hline $\mathrm{C}$ & 15 & 1 & 0.453 & 0.049 & 0.448 & $0 \cdot 374$ \\
\hline
\end{tabular}

auctions rises from about $\$ 1.8$ million in 4-bidder auctions to over $\$ 10$ million, in 10-bidder auctions. While this is consistent with the hypothesis that the winner's curse (which leads to more cautious - higher-bids) dominates the increased competition effect (which leads to more aggressive-lower-bids), a more likely and non-strategic explanation is that these auctions are characterized by selective participation and contract heterogeneity, so that larger projects (which, 
from a pure cost perspective, command larger bids) attract more bidders. This suggests that controlling for contract heterogeneity is crucial to measuring the effects of the winner's curse, and we discuss this issue further below.

\section{Contractor reimbursement schemes: is competitive bidding appropriate? Before} proceeding to discuss specification issues, we consider whether our assumption of competitive bidding is appropriate in the procurement setting, given the schemes used by the NJDOT to reimburse contractors. The contracts offered by the transportation department are characterized by contractor reimbursement guidelines which have both cost-plus (government assumption of all cost overruns above the bid) and fixed price (contractor assumption of all cost overruns above the bid) features. While each contractor submits a scalar bid $b$, he is also required as part of the bid submission process to break down this amount into a vector of unit prices $\vec{p}$ and an associated vector of tasks $\vec{q}$ which he agrees to perform for the payment $b=\vec{p}^{\prime} \cdot \vec{q}$. While bids are ranked (and contracts awarded) solely on the basis of the scalar bid $b$, the contract details (unit prices and quantities) are important at the contract fulfilment stage. ${ }^{13}$ The government assumes all cost increases due to unexpected increases in job quantities $\vec{q}$, but these cost increases are priced out at the unit prices bid by the contractors so that the contractor is bound to supply its services at its submitted unit prices $\vec{p}$; losses arising from unanticipated cost increases are not borne by the government.

These compensation guidelines raise two concerns: first, a moral hazard problem arises since contractors may not keep their costs as low as possible; second, contractors have little incentive to submit cost-based bids for contracts where their eventual payoff is independent of their costs. McAfee and McMillan (1987) pointed out that the first problem will not affect the bidding process, since any rents from post-contractual opportunism should be competed away in equilibrium.

Institutional features of the procurement process tend to alleviate the second problem of noncompetitive bidding. Repeated interactions render reputational effects important in this procurement setting. ${ }^{14}$ While these reputational effects are not a part of our formal model, we feel that the potential loss of future bidding eligibility may counteract contractors' incentives to submit bids which are non-indicative of their costs. In addition, contractors' costs are monitored on a fairly regular basis (every few weeks, from conversations with NJDOT officials). The original submitted bid must already indicate clearly projected materials costs, labour costs, and labour hours required. Deviations from these estimates must be rigorously justified. ${ }^{15}$

Most convincingly, however, the raw data seems to support the competitive-bidding hypothesis. For a subset of the auctions we study, we were also able to obtain data on the expost compensation. The regression equation of the natural logarithm of compensation ${ }^{16}$ on the

13. Helpful conversations with Marty Miller at the NJDOT clarified these institutional details.

14. Many of the contractors in these auctions bid on many contracts over time, and likely derive a large part of their revenues from doing contract work for the state. In our data, we observe 421 distinct bidders, and each firm submits bids in an average of around 15.86 auctions in our data set. Successful bidders are even more active: in our sample, firms which are awarded at least one contract bid in an average of 29.43 auctions.

The NJDOT maintains a list of "prequalified contractors" which all firms must be on in order to be eligible to bid; given that the government observes ex-post compensation from all contracts, it is likely that firms who are judged to have acted opportunistically will be struck off the list. We did not have access to this list, which (naturally) changed over the course of the sample period, due mostly to entry of new contractors.

15. The standard text by Halpin and Woodhead (1998) contains examples of typical cost-plus contracts in Appendix E, as well as a description of cost control/monitoring techniques which are widely used in practice in Chapter 14.

16. Note that we never observe a firm's actual costs: the basis for firms' compensation are the per-unit costs submitted as part of the bid, which presumably already include a margin above actual costs. 
natural logarithm of the winning bids is

$$
\begin{aligned}
\log (\text { compensation }) & =\left(\begin{array}{c}
0 \cdot 0080 \\
(0 \cdot 226)
\end{array}\right)+\left(\begin{array}{c}
1 \cdot 0158 \\
(0 \cdot 0166)
\end{array}\right) \log (\text { winning bid }) \\
R^{2} & =0.928, \quad N=291
\end{aligned}
$$

indicating no systematic overruns (insignificant constant) and a strong correlation between compensation and the bid (as is consistent with competitive bidding). In fact, cost underrunswhich are inconsistent with any post-contractual opportunism scenario-occurred in 132/291 of these auctions. In any case, no evidence of systematic underbidding, which would be reflected in systematic overruns, exists. ${ }^{17}$

\section{SPECIFICATION AND ESTIMATION}

Next, we describe the specific parameterization of contractors' costs which we employ.

Wilson's log-additive model We follow Wilson (1998) in choosing a log-additive form for the cost function $c_{i} .{ }^{18}$ We employ a symmetric version of Wilson's log-additive model, where contractor $i$ 's cost $c_{i}$ is assumed to take the form

$$
c_{i}=a_{i} \times v,
$$

where $a_{i}$ is a bidder $i$ 's private cost from undertaking the project (which could include differences in labour efficiencies between firms) and $v$ is an unknown cost component which is common across all bidders (including, for example, uncertainty in future materials costs). In other words, $c_{i}$ is the product of a common value $(v)$ part and a private value $\left(a_{i}\right)$ component. ${ }^{19}$

We assume that $v$ and the $a_{i}$ 's are independently log-normally distributed: letting $\tilde{v} \equiv \log v$ and $\tilde{a}_{i} \equiv \log a_{i}$, then

$$
\begin{gathered}
\tilde{v}=m+\epsilon_{v} \sim N\left(m, \sigma_{v}^{2}\right) \\
\tilde{a}_{i}=\bar{a}+\epsilon_{a_{i}} \sim N\left(\bar{a}, \sigma_{a}^{2}\right) .
\end{gathered}
$$

Each bidder is assumed to have a noisy signal of her cost of fulfilling the contract terms, $x_{i}$, which has the form

$$
x_{i}=c_{i} \times e_{i} .
$$

Here $x_{i}$ is a contractor $i$ 's noisy estimate of the unknown cost $c_{i}$, and $e_{i}=\exp \left\{\sigma_{e} \xi_{i}\right\}$ where $\xi_{i}$ is an (unobserved) error term that has a normal distribution with mean 0 and variance 1 . If we let $\tilde{c}_{i} \equiv \log c_{i}$ and $\tilde{x}_{i} \equiv \log x_{i}$ then, conditional on $\tilde{c}_{i}, \tilde{x}_{i}=\tilde{c}_{i}+\epsilon_{e_{i}} \sim N\left(\tilde{c}_{i}, \sigma_{e}^{2}\right)$. Since $m$ and $\bar{a}$ always appear together as a sum in this manner, we will not be able to estimate both parameters, but just their sum $\mu \equiv m+\bar{a} \cdot .^{20}$

17. In the context of the bidding example above, however, underruns occur chiefly because a job has required less time or materials than the contractor originally anticipated in submitting its bid.

18. See also Wilson (1983), in which a similar specification was considered for a symmetric first-price auction.

19. Given that $c_{i}$ represents firm $i$ 's costs, there is a natural interpretation of the common component $v$ as an index of unknown future input prices, and $a_{i}$ as a "quantity index" of inputs (where the amount of each input required depends on firms' efficiency levels). Standard assumptions (cf. Varian (1992, Chapter 9)) on the production technology enable one to aggregate the inner product of vectors of inputs and input prices as the product of a single price and quantity index.

20. Here $m$, the mean of the prior distribution of $v$, could potentially include a "cost-padding" component which represents the bidders' common opportunities to engage in cost-inflation activities while undertaking the project. In this way, we accommodate moral hazard issues which are otherwise absent from our analysis. We feel that this is adequate since, as McAfee and McMillan (1987) note, equal cost-padding (or "shirking") opportunities across bidders will simply shift up bidders' costs by an equal amount, and not affect equilibrium bidding. 
The relative magnitudes of the $\sigma$ 's indicate the relative importance of common-value and private-value components in bidders' preferences. As $\sigma_{e}$ tends to 0 , bidders' uncertainty about their costs disappears, and the model resembles a pure (affiliated) private-value model. As $\sigma_{a}$ tends to 0 , the importance of the idiosyncratic component in bidders' valuations falls, implying a pure common-value model. As $\sigma_{v}$ tends to 0 , bidders' uncertainty about the common component $v$ disappears, making the model an independent private-value model, but one in which bidders imperfectly observe their private values (since $\sigma_{e}>0$ ). ${ }^{21}$

A similar "log-additive" approach was also taken in the general "conditionally independent private-information" models considered in Li et al. (2000). Generally, both our approach and theirs employ the assumption that bidders observe only a one-dimensional signal $x$, although correlation among the signals across bidders is induced by a two-factor log-additive model. This assumption that the signal is one-dimensional is a crucial one which ensures tractibility of the model. $^{22}$

Identification Next we discuss identification of the model parameters, especially the crucial parameters $\left(\sigma_{v}, \sigma_{a}, \sigma_{e}\right)$ which indicate the importance of common- and private-value components in bidders' preferences. It is generally difficult in nonlinear parametric models to be very explicit about what types of variation in the data serve to identify particular parameters. Therefore we address the identification issue by simulating our model in order to investigate how changes in the parameter values affect the moments and quantiles of the $s_{n}(x ; \theta)$ function, which form the basis of our estimation strategy. This exercise will alert us to parameters which are badly identified as those which spark no independent change in the (simulated) $s_{n}(x ; \theta)$ function.

Our large auction data set contains variation along two dimensions: bidders and number of participants. Our symmetry assumption implies that bidders are homogeneous, so that we do not exploit the fact that we observe an identical bidder across many bidding situations. ${ }^{23}$ Variation in the number of participants across auctions drives heterogeneity in bidding behaviour across contracts of a given worktype: for a given bidder, equilibrium bidding strategies in the low-price, sealed-bid auction model described in the previous section will differ depending on the number of rival bidders. Therefore, the distributions of the equilibrium bids will not be identical across auctions with different number of participants, even among all contracts of the same worktype. This is an important source of variation which we could exploit to identify the parameters. ${ }^{24}$

However, this variation in $N$ may not be wholly exogenous: for example, if contractors selectively participate in auctions of larger contracts, a spurious positive correlation between $N$ and observed bids arises which could be misattributed to the effects of the winner's curse. Since we do not observe any measures of contract heterogeneity in our data set, these considerations

21. In short, this is a private-value model where bidders do not observe their private-value model; it can be turned into a standard PV model where we redefine the private value as $E\left(c_{i} \mid x_{i}\right)$

22. In short, we assume that bidder $i$ observes only one signal $x_{i}$, and cannot distinguish between its two components $a_{i}$ and $v \times e_{i}$. A growing literature on auctions with multi-dimensional signals has shown that, outside of specific examples, it is difficult to characterize equilibrium in these situations. For example, Pesendorfer and Swinkels (2000) employ a model where a bidder's type consists of two quantities: a private-value component and a (discrete) signal of the object's value. Indeed, they are only able to prove existence of $\epsilon$-equilibria in this setting. The model of Wilson (1998) also assumes bidders to observe both a private value as well as a signal of their unknown valuation, but the equilibrium he describes hinges upon his assumption that bidders have diffuse priors on the common value $v$, as well as log-normality. Finally, the difficulties of multi-dimensional types extend far beyond auctions into mechanism design in general; see Armstrong (1996) and Rochet and Stole (2000) for discussions.

23. Such variation will be important once we investigate the asymmetric case, which is the topic of ongoing research.

24. Given the sizeable variation in the number of bidders observed in the auction data set, even for contracts of a given worktype, the possibility arises that bidders may not be aware of the number of rivals when they submit their bid. Hendricks et al. (2000) derive the equilibrium bidding strategies for a symmetric affiliated value auction. In what follows (in the appendix) we consider a specification which allows for this possibility. 
suggest that controlling for unobserved heterogeneity is crucial to measuring the effects of the winner's curse.

In Figure 1, we explore the effects of $\sigma_{v}, \sigma_{a}$ and $\sigma_{e}$ on the equilibrium bids holding $N$ fixed (at six), in order to address the identification of these parameters without relying on variation in $N$. Equilibrium strategies are computed for different combinations of the $\sigma$ 's. As we would expect, the effects of changing $\sigma_{a}$ and $\sigma_{e}$ differ depending on whether $\sigma_{v}$ is far or close to zero. When $\sigma_{v}=1$ (as in the top graph) the effect of an increase in $\sigma_{e}$ is generally to increase bids (the dotted-cross line, which has the highest value of $\sigma_{e}$, is the highest bid function). This is completely in line with the effects of the winner's curse: here, an increase in the noisiness of the signals (as measured by $\sigma_{e}$ ) leads to more cautious (i.e. higher) bids.

From the bottom graph, however, we see that when common values are not important (we set $\sigma_{v}=0$ ), these winner's curse effects are not present at all. Here, note that the dotted-cross line remains low throughout, demonstrating that an increase in the signal's "noisiness" actually leads to more competitive bidding over the entire range of signals.

These graphs demonstrate that perturbations in the basic parameters in the log-additive model do lead to changes in the shapes and/or magnitudes of the equilibrium bid functions, even without variation in $N$. This suggests that, from a computational point of view, the parameters are indeed identified and estimable.

\subsection{Estimation approach: monotone quantile estimator}

Equation (2) shows how the joint distribution $F\left(x_{1}, c_{1}, \ldots, x_{n}, c_{n} ; \theta\right)$ induces a joint distribution for the equilibrium bids, which we observe. Given that the distribution of $s_{n}(x ; \theta)$ is likely to be quite asymmetric, even if we assume any individual $x$ to be symmetrically distributed, we estimate the parameters via quantile restrictions, which try to match the "shapes" of the distributions of the observed bids and the $s_{n}(x ; \theta) .{ }^{25}$ As is well known, quantile estimators are more robust to outliers in the data than estimators based on matching the centred moments.

Two insights drive our estimation procedure. First, the quantiles of a distribution $F(x)$ are invariant to monotonic transformations of the random variable $x$. Second, for our symmetric first-price auction, the equilibrium bidding strategies $s_{n_{i}}(x ; \theta)$ for auction $i$ (which had $n_{i}$ participants) are monotonic transformations of the unobserved signals $x \sim F(x ; \theta)$, where $F(\cdots)$ denotes the marginal distribution for a single signal. ${ }^{26}$ In particular, $q_{\tau_{k}}^{n_{i}}(\theta)$, the $\tau_{k}$-th quantile of the equilibrium bid function for the $i$-th auction, is just $s_{n_{i}}\left(x_{\tau_{k}}, \theta\right)$, the equilibrium bid function evaluated at $x_{\tau_{k}}$, the $\tau_{k}$-th quantile of the marginal distribution $F_{n_{i}}(x ; \theta)$.

Our estimator $\hat{\theta}$ minimizes the quantile objective function

$$
Q(\theta)=\sum_{i=1}^{T} \sum_{j=1}^{n_{i}} \sum_{k=1}^{K} \rho_{\tau_{k}}\left[b_{i j}-q_{k}^{n_{i}}\left(x_{\tau_{k}} ; \theta\right)\right]
$$

where the function $\rho_{\tau_{k}}(\cdot)$ is defined as

$$
\rho_{\tau_{k}}(x)=\left[\tau_{k}-1(x \leq 0)\right] x .
$$

There are two important features of this estimator. First, it alleviates (dramatically) the computational burden associated with simulating the moments of the equilibrium bid distribution. ${ }^{27}$ Second, this estimator has a formal appeal since the quantile restrictions follow

25. Recall that $\log x$ is normally distributed.

26. For our log-normal model, $x_{\tau_{k}}=\exp \left(\sigma \Phi^{-1}\left(\tau_{k}\right)+\mu\right)$, where $\Phi(\cdot)$ is the standard normal cumulative distribution function, and $\mu$ and $\sigma$ are, respectively, the mean and variance of $\log x_{\tau_{k}}$.

27. More precisely, to compute $s_{n_{i}}\left(x_{\tau_{k}} ; \theta\right)$, the $\tau_{k}$-th quantile of the equilibrium bid distribution, the bid function need be evaluated only once, at $x_{\tau_{k}}$. In contrast, in order to simulate $E_{x} s_{n_{i}}(x ; \theta)$, the mean equilibrium bid, the bid 


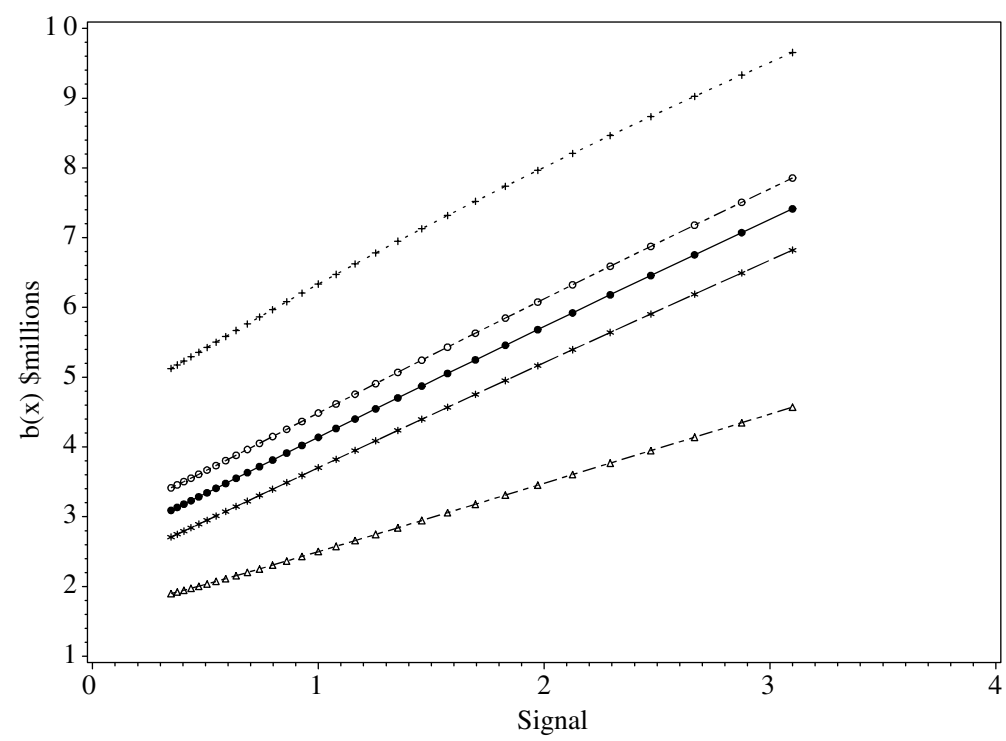

Legend: $-\bullet-\bullet, \sigma_{v}=1, \sigma_{a}=1, \sigma_{e}=1 ;-\circ-\circ-, \sigma_{v}=1, \sigma_{a}=0, \sigma_{e}=1 ; \triangle-\triangle-\triangle-, \sigma_{v}=1, \sigma_{a}=1$,

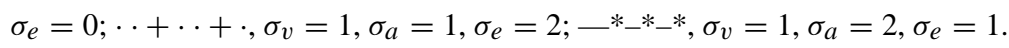

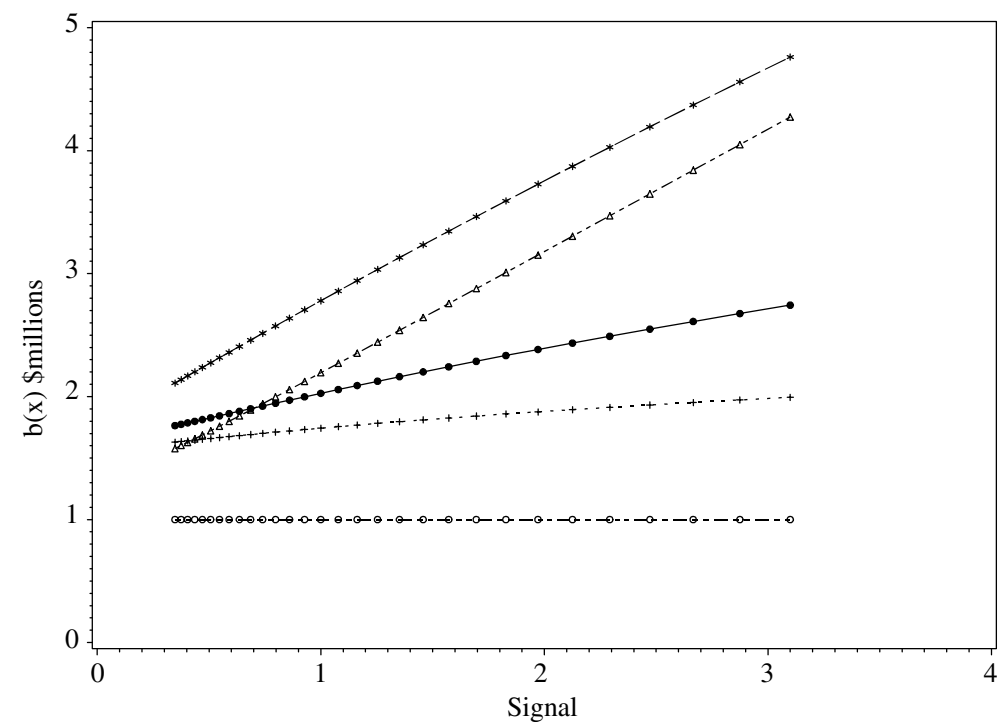

Legend: $-\bullet-\bullet, \sigma_{v}=0, \sigma_{a}=1, \sigma_{e}=1 ;-\circ-\circ-, \sigma_{v}=0, \sigma_{a}=0, \sigma_{e}=1 ; \triangle-\triangle-\triangle-, \sigma_{v}=0, \sigma_{a}=1$,

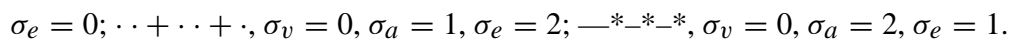

FIGURE 1

How bid functions vary in $\sigma_{a}$ and $\sigma_{e}$, for $N=6$

wholly from the theoretical result that the bidding strategies are monotonic transformations of the signals in equilibrium. Such an estimation approach is potentially very useful in other incomplete

function must be computed at $S$ random draws from the marginal signal distribution, where $S$ is the number of draws used to compute the simulated mean. Therefore, the monotone quantile estimator reduces the computational burden by an order of $S$ by obviating the need to simulate the moments of the equilibrium bid distribution. 
TABLE 3

Parameter estimates: baseline specification. Standard errors in parentheses

\begin{tabular}{cccr}
\hline $\begin{array}{c}\text { Worktype: } \\
\text { Parameter }\end{array}$ & A & B & \multicolumn{1}{c}{ C } \\
\hline$\sigma_{v}$ & $2 \cdot 4529(0 \cdot 3883)$ & $1 \cdot 4877(0 \cdot 1280)$ & $1 \cdot 3811(0.0523)$ \\
$\sigma_{a}$ & $0 \cdot 0024(0 \cdot 0038)$ & $0 \cdot 0064(0 \cdot 0084)$ & $0 \cdot 0376(0 \cdot 1006)$ \\
$\sigma_{e}$ & $0 \cdot 9771(0 \cdot 0007)$ & $0 \cdot 1612(0 \cdot 1075)$ & $0 \cdot 4317(0 \cdot 2191)$ \\
$\mu$ & $-0.4261(0 \cdot 0309)$ & $0 \cdot 0694(0 \cdot 0190)$ & $-0 \cdot 4803(0 \cdot 2095)$ \\
Simulation draws: $^{a}$ & 50 & 50 & 50 \\
\hline
\end{tabular}

${ }^{a}$ Number of simulation draws used in calculating $v_{n}(x, x ; \theta)$.

information settings where the equilibrium strategies (or the "policy functions") are monotonic transformations of the unobserved types: for example, nonlinear pricing (and, more generally, mechanism design) models appear very well suited to this approach. ${ }^{28}$

\section{ESTIMATION RESULTS}

Table 3 presents estimates of the four parameters of the benchmark model. In the discussion below, standard errors are enclosed in square brackets ([…]).

Recall that the model resembles a private-value model as $\sigma_{e}$ tends to 0 , and resembles a pure common-value model as $\sigma_{a}$ tends to 0 . The small estimated $\sigma_{a}$ for all three types of contracts (0.0024 [0.0038] for worktype A; 0.0064 [0.0084] for worktype B; and 0.0376 [0.1006] for worktype C) suggests that all these auctions can be described as predominantly pure commonvalue auctions. ${ }^{29}$

While striking, this finding is not wholly surprising, given the upward trend in both average and median bids observed in the raw data (cf. Table 2). Abstracting away from all else, this upward trend can be attributed to the less aggressive bidding caused by the winner's curse, which only occurs in common-value auctions. However, a more likely and non-strategic explanation is that these auctions are characterized by selective participation and contract heterogeneity, so that larger projects (which, from a purely cost perspective, command larger bids) attract more bidders. This suggests that controlling for contract heterogeneity is crucial to measuring the effects of the winner's curse. Unfortunately, we were not able to obtain engineering estimates of the costs associated with each contract, which Bajari (1998) and Jofre-Bonet and Pesendorfer (1999) used to control for contract heterogeneity in their papers. Therefore, we control for this heterogeneity in several ways, first by allowing the (parameters which characterize the) distribution of signals in auction $i$ to depend explicitly on $n_{i}$, the number of participants in auction $i .^{30}$

Robustness check 1: controlling for selective participation First, we allow $\mu_{i}$, the mean of the $\log$ - $\operatorname{costs} c_{i}$ in auction $i$, to have a quadratic trend in $n_{i}$, the number of participants

28. The same insight appears implicit in the War of Attrition example considered in Milgrom and Weber (1985). Powell (1984) used the same intuition to derive a distribution-free least-absolute deviations (LAD) estimator for censored linear regression models: in his case, the monotonic censoring operation preserved the quantiles between the distribution of the additive error term and the (censored) dependent variable. Manski (1994, Section 4.4) labels these "quantile independent monotone models".

29. In general, given the parameter restrictions that $\sigma_{a}, \sigma_{v}, \sigma_{e}$ are all $\geq 0$, it is not always straightforward to test whether any of the $\sigma$ 's are equal to zero, the lower bound of the parameter space. However, nonstandard tests need be employed only when testing joint hypotheses that two or more of the $\sigma$ 's are equal to zero (cf. Andrews (1998), Wolak (1989)); a standard one-sided $t$-test is valid for univariate tests.

30. While an explicitly structural model of contractors' participation decisions is beyond the scope of this paper, a model of bidder participation based on reserved price is discussed in the appendix. 
TABLE 4

Parameter estimates. Robustness check 1: control for selective participation. Parametrize $\mu=\mu_{0}+\mu_{1} * n+\mu_{2} * n^{2}$. Standard errors in parentheses

\begin{tabular}{|c|c|c|c|}
\hline $\begin{array}{l}\text { Worktype: } \\
\text { Parameter }\end{array}$ & A & B & $\mathrm{C}$ \\
\hline$\sigma_{v}$ & $2 \cdot 2621(0 \cdot 1898)$ & $0 \cdot 7847(0 \cdot 1038)$ & $0.9054(0.0349)$ \\
\hline$\sigma_{a}$ & $0 \cdot 1294(0 \cdot 0824)$ & $1 \cdot 1382(0 \cdot 1174)$ & $0.9778(0.0078)$ \\
\hline$\sigma_{e}$ & $0 \cdot 5196(0 \cdot 1675)$ & $0 \cdot 4030(0 \cdot 2445)$ & $0 \cdot 3622(0 \cdot 0740)$ \\
\hline$\mu_{0}$ & $-1 \cdot 6814(0 \cdot 4086)$ & $0 \cdot 8266(0 \cdot 3000)$ & $-1 \cdot 6563(0 \cdot 3248)$ \\
\hline$\mu_{1}$ & $0 \cdot 3891(0 \cdot 1143)$ & $-0.2759(0.0959)$ & $0.4146(0.0948)$ \\
\hline$\mu_{2}$ & $-0 \cdot 0142(0.0080)$ & $0.0191(0.0095)$ & $-0.0258(0.0063)$ \\
\hline Simulation draws: ${ }^{a}$ & 50 & 50 & 50 \\
\hline
\end{tabular}

${ }^{a}$ Number of simulation draws used in calculating $v_{n}(x, x ; \theta)$.

in auction $i$ :

$$
\mu_{i}=\mu_{0}+\mu_{1} * n_{i}+\mu_{2} * n_{i}^{2}
$$

and estimate $\mu_{0}, \mu_{1}$, and $\mu_{2}$ as parameters. The results from these specifications are given in Table 4.

Allowing the means to differ depending on the number of bidders does lead to changes in the parameter estimates for the important $\sigma$ parameters. While we continue to reject the importance of private values in the worktype A auctions ( $\sigma_{a}$ is estimated to be 0.1294 [0.0824]), we can no longer do so for the auctions of the other types of contracts. The point estimates for $\sigma_{a}$ in the auctions of worktypes $B$ and $C$ contracts are much larger than before $(1 \cdot 1382$ [0.1174] for worktype B, and 0.9778 [0.0078] for worktype C). From these results, we conclude that auctions for highway-work contracts are very close to a pure common-value auction, while both common and private values are important in auctions of bridge repair and paving contracts.

The positive estimates of $\mu_{1}$ for all three worktypes are consistent with the hypothesis that auctions with more bidders feature larger contracts; correspondingly, the negative estimate for the quadratic coefficient $\mu_{2}$ for these worktypes indicates that this positive relationship only holds at smaller values of $n_{i}$.

Robustness check 2: random effects for unobserved contract heterogeneity The preceding specification is still restrictive because all contracts of the same worktype and with the same number of bidders are still assumed to be homogeneous. Therefore, we focus next on a specification which used random effects to control for unobserved heterogeneity across auctions. ${ }^{31}$ More precisely, we assume that $\mu_{i}$, the median of the signal distribution for auction $i$, is drawn from a normal distribution with mean $\eta_{i}$ and standard deviation $\sigma_{\eta_{i}}$, and independent across auctions. ${ }^{32}$ Furthermore, we parametrize $\eta_{i}$ and $\sigma_{\eta_{i}}$ as a function of the number of bidders

31. This is a very common remedy in estimating duration models also, where unobserved heterogeneity can lead to spurious duration dependence (cf. Heckman and Singer (1984)).

32. As suggested by a referee, we also decomposed the correlation among bids into the intra-auction and interauction components, in order to distinguish between the correlation among bids arising from common components that are observed by the bidders but not by the econometrician (unobserved heterogeneity), and the correlation that arises from common components unobserved by the bidders (a common value information structure). If the common component $v$ is not observed by the bidders (as in an affiliated signals information structure), then bids are uncorrelated across auctions but correlated within auctions. If $v$ is observed by the bidders but not by the econometrician, then the opposite could be true. For all three worktypes, we found that our measure of intra-auction correlation was much larger than the measure of inter-auction correlation, indicating that most of the correlation in the bids is within the auctions. This suggests that affiliation between the signals may be more important than unobserved heterogeneity in these auctions. 
TABLE 5

Parameter estimates. Robustness check 2: random effects. Standard errors in parentheses

\begin{tabular}{|c|c|c|c|}
\hline $\begin{array}{l}\text { Worktype: } \\
\text { Parameter }\end{array}$ & A & B & $\mathrm{C}$ \\
\hline$\sigma_{v}$ & $0.6741(0.0148)$ & $0.4583(0.0900)$ & $0.0634(0.0335)$ \\
\hline$\sigma_{a}$ & $1.1938(0.0236)$ & $0.3298(0 \cdot 1769)$ & $0.5201(0.0311)$ \\
\hline$\sigma_{e}$ & $2 \cdot 3048(0 \cdot 0444)$ & $0.4383(0.0818)$ & $0 \cdot 3455(0 \cdot 0618)$ \\
\hline$\eta_{1}$ & $-2 \cdot 5873(0.0713)$ & $0.9074(0.1116)$ & $-1.5803(0.0312)$ \\
\hline$\eta_{2}$ & $-1.7721(0.0419)$ & $0.3125(0.0241)$ & $-0.9035(0.0174)$ \\
\hline$\eta_{3}$ & $-1.4274(0.0305)$ & $0.0776(0.0330)$ & $-0.6331(0.0130)$ \\
\hline$\eta_{4}$ & $-1 \cdot 1247(0 \cdot 0221)$ & $-0 \cdot 1155(0 \cdot 0669)$ & $-0.4082(0.0106)$ \\
\hline$\eta_{5}$ & $-0.8639(0.0177)$ & $-0 \cdot 2670(0 \cdot 0990)$ & $-0.2287(0.0102)$ \\
\hline$\eta_{6}$ & $-0.6451(0.0180)$ & $-0.3768(0 \cdot 1275)$ & $-0.0946(0.0113)$ \\
\hline$\eta_{7}$ & $-0.4682(0.0213)$ & $-0.4449(0 \cdot 1522)$ & $-0.0059(0.0130)$ \\
\hline$\eta_{8}$ & $-0.3333(0.0259)$ & $-0.4713(0 \cdot 1728)$ & $0.0375(0.0153)$ \\
\hline$\eta_{9}$ & $-0.2404(0.0308)$ & $-0.4560(0.1896)$ & $0.0354(0.0181)$ \\
\hline$\eta_{10}$ & $-0.1893(0.0361)$ & $-0.3990(0 \cdot 2024)$ & $-0.0121(0.0217)$ \\
\hline$\eta_{11}$ & $-0 \cdot 1803(0 \cdot 0418)$ & $-0 \cdot 3004(0 \cdot 2115)$ & $-0.1049(0.0264)$ \\
\hline$\eta_{12}$ & $-0 \cdot 2132(0.0484)$ & $-0 \cdot 1600(0 \cdot 2169)$ & $-0.2432(0.0323)$ \\
\hline$\eta_{13}$ & $-0.2880(0.0562)$ & $0.0221(0 \cdot 2189)$ & $-0.4269(0.0395)$ \\
\hline$\eta_{14}$ & $-0.4048(0.0656)$ & $0 \cdot 2459(0 \cdot 2176)$ & $-0.6559(0.0480)$ \\
\hline$\eta_{15}$ & $-0.5635(0.0766)$ & $0 \cdot 5113(0 \cdot 2136)$ & $-0.9304(0.0579)$ \\
\hline$\sigma_{\eta_{1}}$ & $0 \cdot 1553(0 \cdot 0062)$ & $0 \cdot 3661(0 \cdot 0101)$ & $0.5943(0.0096)$ \\
\hline$\sigma_{\eta_{2}}$ & $0.1553(0.0062)$ & $0.3661(0.0101)$ & $0.5943(0.0096)$ \\
\hline$\sigma_{\eta_{3}}$ & $0.1691(0.0064)$ & $0 \cdot 3675(0 \cdot 0099)$ & $0.5817(0.0081)$ \\
\hline$\sigma_{\eta_{4}}$ & $0 \cdot 1856(0 \cdot 0065)$ & $0.3718(0 \cdot 0094)$ & $0.5689(0.0069)$ \\
\hline$\sigma_{\eta_{5}}^{1 / 4}$ & $0.2052(0 \cdot 0067)$ & $0.3790(0 \cdot 0087)$ & $0.5560(0.0060)$ \\
\hline$\sigma_{\eta_{6}}$ & $0.2288(0 \cdot 0069)$ & $0.3893(0 \cdot 0079)$ & $0.5428(0.0056)$ \\
\hline$\sigma_{\eta_{7}}$ & $0.2571(0 \cdot 0072)$ & $0.4028(0 \cdot 0070)$ & $0.5296(0.0057)$ \\
\hline$\sigma_{\eta_{8}}$ & $0.2911(0 \cdot 0077)$ & $0.4200(0 \cdot 0064)$ & $0.5162(0.0062)$ \\
\hline$\sigma_{\eta_{9}}$ & $0.3323(0.0086)$ & $0.4413(0.0067)$ & $0.5027(0.0069)$ \\
\hline$\sigma_{\eta_{10}}$ & $0.3823(0 \cdot 0101)$ & $0.4672(0.0087)$ & $0.4892(0.0077)$ \\
\hline$\sigma_{\eta_{11}}$ & $0.4434(0 \cdot 0126)$ & $0.4983(0 \cdot 0124)$ & $0.4757(0.0086)$ \\
\hline$\sigma_{\eta_{12}}$ & $0.5182(0.0166)$ & $0.5356(0.0178)$ & $0.4621(0.0096)$ \\
\hline$\sigma_{\eta_{13}}$ & $0.6104(0.0226)$ & $0.5800(0 \cdot 0251)$ & $0.4486(0 \cdot 0105)$ \\
\hline$\sigma_{\eta_{14}}$ & $0.7248(0.0315)$ & $0.6329(0.0346)$ & $0.4350(0.0114)$ \\
\hline$\sigma_{\eta_{15}}$ & $0 \cdot 8674(0 \cdot 0442)$ & $0 \cdot 6958(0 \cdot 0467)$ & $0.4216(0 \cdot 0122)$ \\
\hline Simulation draws: ${ }^{a}$ & 50 & 50 & 50 \\
\hline
\end{tabular}

${ }^{a}$ Number of simulation draws used in calculating $v_{n}(x, x ; \theta)$.

$n_{i}$ in auction $i$ :

$$
\begin{aligned}
\eta_{i} & =\gamma_{0}+\gamma_{1} * n_{i}+\gamma_{2} * n_{i}^{2} \\
\sigma_{\eta_{i}} & =\exp \left(\gamma_{3}+\gamma_{4} * n_{i}+\gamma_{5} * n_{i}^{2}\right)
\end{aligned}
$$

where $\left(\gamma_{0}, \ldots, \gamma_{5}\right)$ are parameters to be estimated. Note that this specification allows $\mu_{i}$ (the median signal for auction $i$ ) to be a random (across auctions, and from the econometrician's point of view) function of the number of bidders $n_{i}$. In the previous specification (equation (6)), the median bid $\mu_{i}$ is a deterministic function of $n_{i}$ (and the same across all auctions with the same $n_{i}$ ). We believe that by allowing the signal distribution to be shifted explicitly by the number of bidders $n$, we are "handicapping" our model against a finding of winner's curse, so that any evidence of winner's curse which persists could be interpreted as strong evidence.

Table 5 contains parameter estimates from this specification. Instead of reporting estimates of $\gamma_{1}, \ldots, \gamma_{5}$ directly, we report the more easily interpretable estimates of $\eta_{M}$ and $\sigma_{\eta_{M}}$, for 
$M=1, \ldots, 15$. Importantly, the above result that worktype A auctions can be described as almost pure common-value auctions disappears in this set of results. For these auctions, it now appears that the variation in the private component (as parametrized by $\sigma_{a}: 1 \cdot 1938$ [0.0236]) and the noisiness in the signals (measured by $\sigma_{e}: 2.3048$ [0.0444]) contribute more to the variation in the stochastic costs across bidders than uncertainty regarding the common component $v$ (as parametrized by $\left.\sigma_{v}: 0 \cdot 6741[0 \cdot 0148]\right)$.

For worktype $\mathrm{B}$, we continue to find that both private and common components are important, while for the worktype $\mathrm{C}$ auctions, we now find that $\sigma_{v}$, while marginally statistically different from zero $(0.0634$ [0.0335]), is very small in magnitude, making them similar to IPV auctions. Generally speaking, the worktype A contracts are longer in duration and larger in magnitude than the worktype B or C contracts, which support the finding that both CV as well as PV components are important in contractors' cost functions. Below, we will graphically consider the qualitative differences in these magnitudes in terms of predicted bids.

As for the unobserved heterogeneity parameters, the estimates indicate that for the worktype A contracts, the means of the heterogeneity distribution grow larger as the number of bidders increases, supporting the selective participation hypothesis (i.e. that larger contracts attract more contractors). However, the increasing values of $\sigma_{\eta_{M}}$ suggest that there is a greater degree of heterogeneity in auctions attracting a larger number of bidders. While the results are qualitatively similar for worktype B, they are generally reversed for worktype C. Encouragingly, these results correspond to the patterns observed in the raw data (as given in columns 4 and 5 of Table 2), suggesting that we are, indeed, adequately controlling for contract heterogeneity.

In the appendix, we consider two additional robustness checks: controlling for potential vs. actual competition, and controlling for observed heterogeneity (for the worktype A auctions only). Since the results from these specifications do not differ greatly from the random effects results from Table 5, we will not discuss them here.

Model fit In Section 4 above, we note that parametric restrictions of our log-normal model play an important role in identifying the parameters of the model. Therefore, before proceeding, we check that our chosen parametric specification indeed fits the observed data. In Figure 2, we plot the actual and predicted median bids, by worktype and across different number of bidders. The predicted median bids were calculated from the estimation results reported in Tables 4 and $5 .{ }^{33}$ In general, the predicted and actual bids correspond reasonably closely, with the Table 5 results fitting noticeably better.

The "hump" from 8-10 bidders in the actual worktype A auctions are missed by both specifications, but the predicted values are close at a smaller number of bidders. For the worktype B contracts, the Table 5 results fit remarkably close for auctions with less than 10 bidders. For the worktype $\mathrm{C}$ contracts, the Table 5 results also fit reasonably well, across the whole range of cost signals. In what follows, therefore, we focus on the Table 5 results.

\section{INCREASING COMPETITION AND EQUILIBRIUM BIDDING}

\subsection{Increasing competition and individual bids}

First, we examine how individual contractor bids would be potentially affected by increases in the number of competitors, i.e. whether $s_{n}(x)$ is increasing or decreasing in $n$, fixing the signal $x$. We are unaware of any general comparative static results. Previously, Smiley (1979, Chapter 3), Matthews (1984), and Pinkse and Tan (2000) have shown that the sign can go

33. For the Table 5 results, we evaluate the bid functions at the mean random effect, i.e. assuming $\mu_{i}=\gamma_{i}$. 

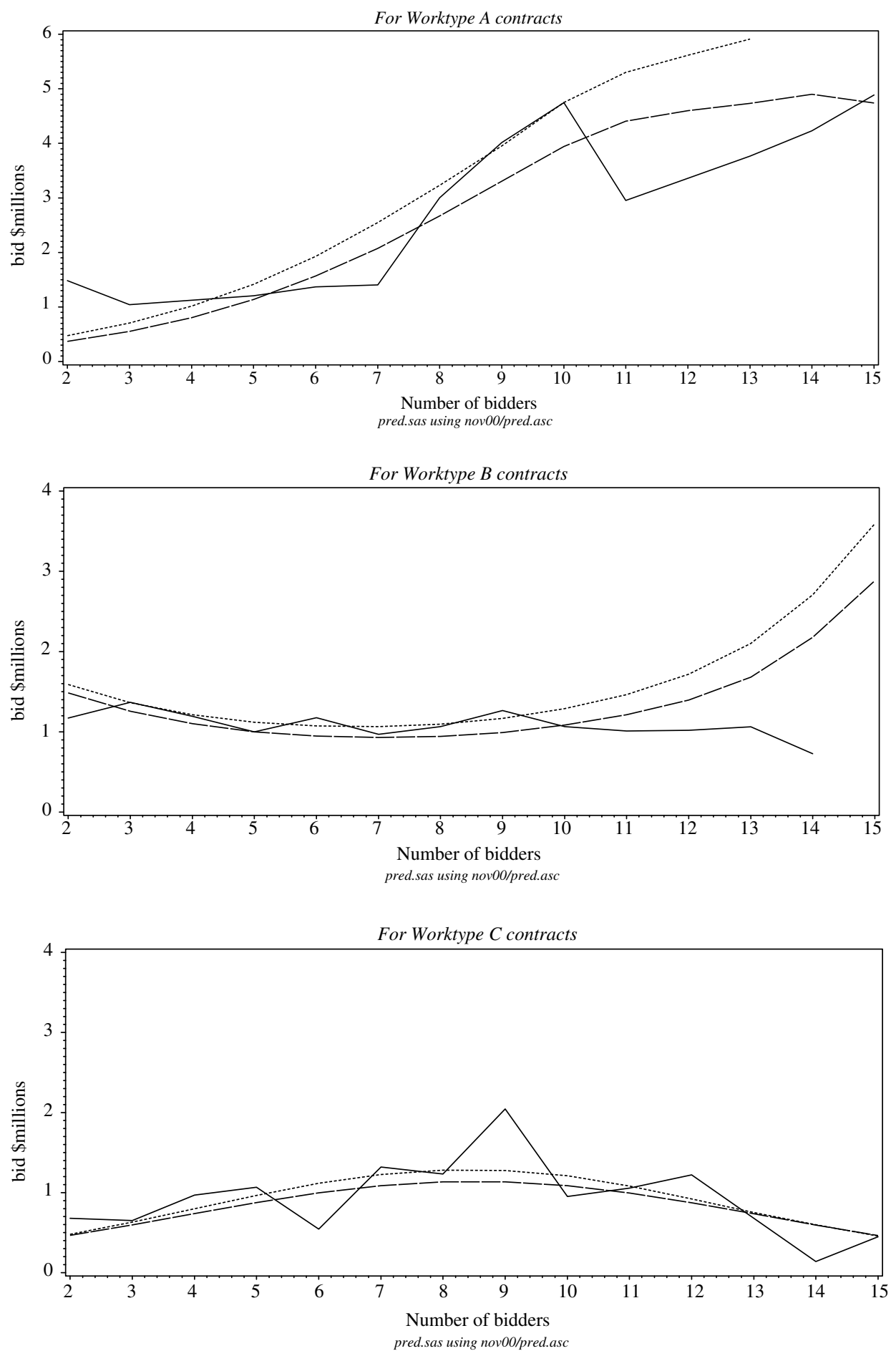

FIGURE 2

Predicted vs. actual bid functions: using Tables 4 and 5 results. Legend: actual median bid (from Table 2; solid line); predicted median bid using Table 4 results (dotted line); predicted median bid using Table 5 results (dashed line) 
either way, depending on the parametric assumptions. ${ }^{34}$ Since our information structure is more complicated than that considered by these authors, we treat this as an open question which we address empirically.

Equilibrium bid functions We simulate the equilibrium bidding function $s_{n}(x ; \theta)$ function via formula (2) for the results from Table 5. The graphs are shown in Figure 3. In order to isolate the pure effect of the winner's curse, we zero out the coefficients attached to the number of bidders (i.e. $\left.\gamma_{1}, \gamma_{2}, \gamma_{4}, \gamma_{5}\right)$ in these simulations. Clearly, the shapes of the graphs vary noticeably over the three worktypes.

For worktypes $\mathrm{A}$ and $\mathrm{B}$, the importance of uncertainty regarding a common component in costs is reflected in the fact that the equilibrium bid functions for these cases are increasing in the number of bidders $n$, across the range of signals; for instance, the equilibrium bid function evaluated at $\log x=-1.0$ rises from about $\$ 0.25$ million with two bidders to over $\$ 1$ million in ten-bidder auctions, a $400 \%$ increase; the magnitude of increase is even greater for the worktype B auctions. We attribute this increase primarily to the winner's curse effect. ${ }^{35}$

On the other hand, the graph for worktype $\mathrm{C}$ reflects the finding that private values are important in these auctions. At low values of $x$, the equilibrium bids are falling in $n$, as we would expect in pure private value auctions. At large levels of $x$, however, some of the bid functions cross, indicating that the winner's curse seems to be more important in this range of $x$. For example, at $\log (x)=-2 \cdot 0$, the worktype B equilibrium bid function for $n=10$ lies below that for $n=6$ (indicating that the competitive effect dominates), but at $\log (x)=-1.0$ the bid function for $n=10$ has crossed over the $n=6$ bid function. The winner's curse effect is stronger at larger value of $x$ : for a given $n$, the probability of winning is smaller as signals get larger, which implies that as $n$ increases the competitive effect will be relatively weaker upon bidders with larger signals, and winning an auction with a less optimistic signal (i.e. higher $x$ ) conveys worse news than winning with a more optimistic signal (i.e. lower $x$ ).

Equilibrium mark-ups Some additional insights of these results are obtained by investigating the bid "mark-ups" implied by our results, where we define the mark-up to be $\frac{b\left(x_{i}\right)-E\left[c_{i} \mid x_{i}\right]}{b\left(x_{i}\right)}$. Here, $E\left[c_{i} \mid x_{i}\right]$ is the expected project cost to bidder $i$ based just upon his signal $x_{i}$, which we take as a "naive" estimate which bidder $i$ might have bid were he incognizant of the winner's curse.

In Table 6, equilibrium mark-ups for the median bidder were calculated at different values of $\sigma_{e}$, which parameterizes the noisiness of contractors' signals regarding their unknown costs, with a larger $\sigma_{e}$ corresponding to greater uncertainty. The mark-ups were calculated after reducing $\sigma_{e}$ by one-half (column 4) and then by $90 \%$ (column 5). Note that the reduction in uncertainty reduces the equilibrium mark-ups for the worktype A auctions dramatically (for 7-bidder auctions, the mark-up falls from over 51-33.6\% when $\sigma_{e}$ is cut in half, and down to just $10.8 \%$ when $\sigma_{e}$ is at one-tenth of its estimated value). This illustrates how a reduction in

34. Smiley (1979) gave examples of multiplicative bid functions where $s_{n}(x)$ decreases in $n$ (i.e. more aggressive bidding), whereas Matthews (1984) focuses on the uniform distribution where $s_{n}(x)$ increases in $n$ (i.e. less aggressive bidding). Pinkse and Tan (2000) characterize general conditions under which the latter occurs in affiliated private-value settings, with the striking implication that common values are not required to obtain equilibrium bidding behaviour which becomes less aggressive as competition increases.

35. As noted above, PT's affiliation effect can also cause bids to rise in $n$, even in the private-values setting. It is difficult to verify PT's conditions (cf. Lemma 1 in PT) analytically for our log-additive model, and so to gauge the importance of this affiliation effect, we simulated the bid functions setting $\sigma_{e}=0$ (which turn all the models into affiliated private-values models). Across all three worktypes, the results indicated that the bid functions, after making this change, were all decreasing in $n$, suggesting that the affiliation effect is absent. As a result, we mostly attribute the increase in equilibrium bids shown in Figure 3 to the winner's curse. 

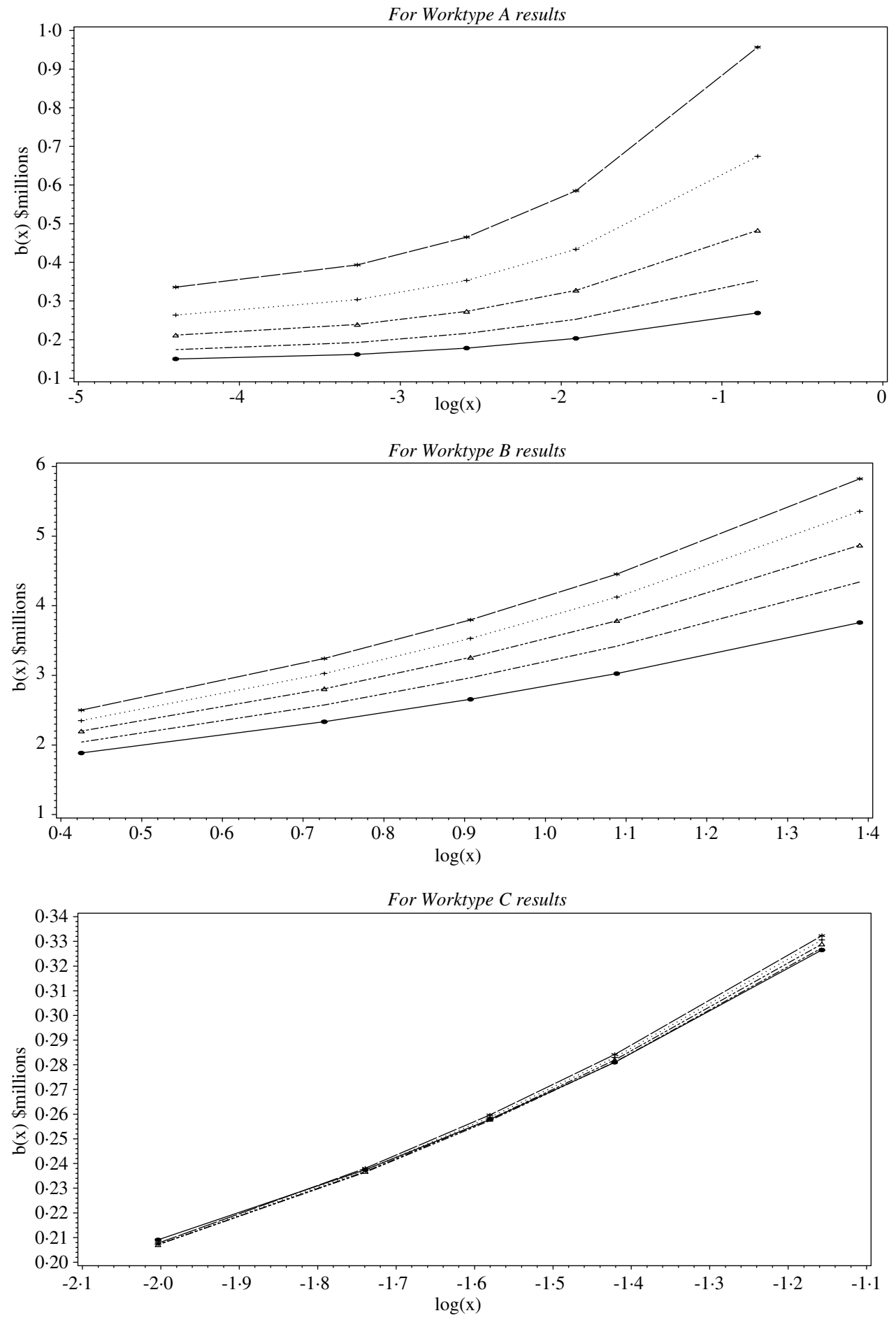

FIGURE 3

Equilibrium bid functions: simulated using Table 5 results. Legend: - $\bullet-\bullet-$, two bidders; - - — - —, four bidders; $\triangle-\triangle-\triangle-$, six bidders; $\cdots+\cdots+\cdot$, eight bidders; $-{ }_{*}{ }_{-} *_{-} *$, ten bidders 
TABLE 6

Equilibrium mark-ups: the effect of reduction in uncertainty

\begin{tabular}{ccccc}
\hline Worktype & \# Bidders & $\begin{array}{c}\text { Mark-up: } \\
\sigma_{e}\end{array}$ & $\begin{array}{c}\text { Mark-up: } \\
0.5^{*} \sigma_{e}\end{array}$ & $\begin{array}{c}\text { Mark-up: } \\
0.1 * \sigma_{e}\end{array}$ \\
\hline A & 2 & 0.155 & 0.168 & 0.256 \\
A & 3 & 0.227 & 0.181 & 0.198 \\
A & 4 & 0.303 & 0.209 & 0.159 \\
A & 5 & 0.374 & 0.246 & 0.133 \\
A & 7 & 0.511 & 0.336 & 0.108 \\
A & 10 & 0.676 & 0.467 & 0.103 \\
A & 12 & 0.736 & 0.513 & 0.108 \\
A & 15 & 0.823 & 0.612 & 0.143 \\
B & 2 & 0.010 & 0.036 & 0.041 \\
B & 3 & 0.066 & 0.070 & 0.053 \\
B & 4 & 0.113 & 0.099 & 0.064 \\
B & 5 & 0.153 & 0.123 & 0.074 \\
B & 7 & 0.226 & 0.161 & 0.087 \\
B & 10 & 0.307 & 0.190 & 0.085 \\
B & 12 & 0.326 & 0.184 & 0.070 \\
B & 15 & 0.380 & 0.181 & 0.041 \\
C & 2 & 0.168 & 0.118 & 0.129 \\
C & 3 & 0.166 & 0.091 & 0.100 \\
C & 4 & 0.166 & 0.075 & 0.081 \\
C & 5 & 0.167 & 0.064 & 0.068 \\
C & 7 & 0.169 & 0.053 & 0.055 \\
C & 10 & 0.173 & 0.055 & 0.056 \\
C & 12 & 0.176 & 0.068 & 0.069 \\
C & 15 & 0.180 & 0.124 & 0.128 \\
\hline
\end{tabular}

uncertainty reduces the winner's curse, and therefore the "risk premia" which bidders demand in this market. Similar trends are present for the worktype B auctions.

For worktype $\mathrm{C}$ auctions, however, a reduction in mark-ups is not an obvious consequence of a reduction in uncertainty: for most $n$, the mark-ups remain largely unchanged when going from $0.5 * \sigma_{e}$ to $0.1 * \sigma_{e}$. This emphasizes the point that when private-value components in costs are important, winner's curse concerns are not significant in auctions with few bidders, so that equilibrium mark-ups in these cases are attributable in large part to "market power". When the number of bidders increases, however, winner's curse effects become more important, and a reduction in uncertainty from $\sigma_{e}$ to $0.5 \sigma_{e}$ brings about a larger fall in equilibrium mark-ups just as in the worktype A/B cases. Next, we explicitly explore what these effects imply about government procurement costs.

\subsection{Increasing competition and project procurement costs}

In procurement, common wisdom dictates that increasing the number of contractors would lower project costs. This is true for private-value models but, given the results above (for worktypes A and $\mathrm{B}$ at least), one questions whether this is a wise policy for reducing project costs auctions where common values are important. Next, we present results from simulations of the winning bid in auctions in which the number of competitors is varied. We do this for the results in Table 5, and graph the simulated bids in Figure 4.

For the worktype A results, the average of the simulated winning bids is generally increasing in $n$, indicating that procurement costs would rise if the government invites more competition. The median winning bid rises from about $\$ 0.20$ million with two bidders to $\$ 0.35$ million once 10 


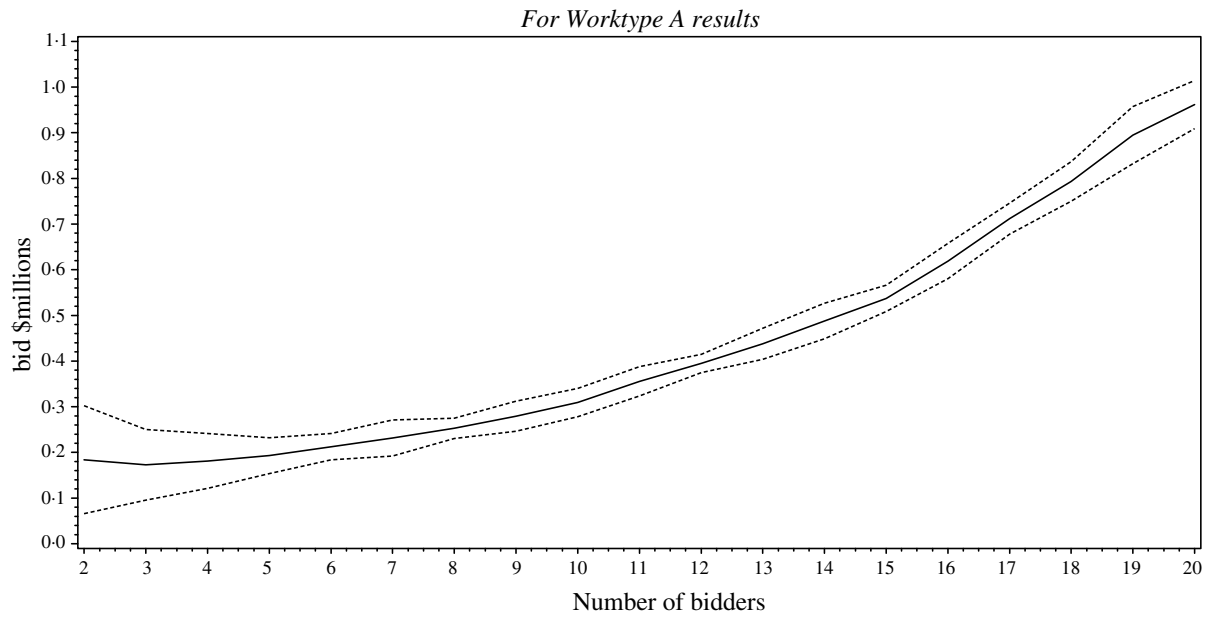

For Worktype B results

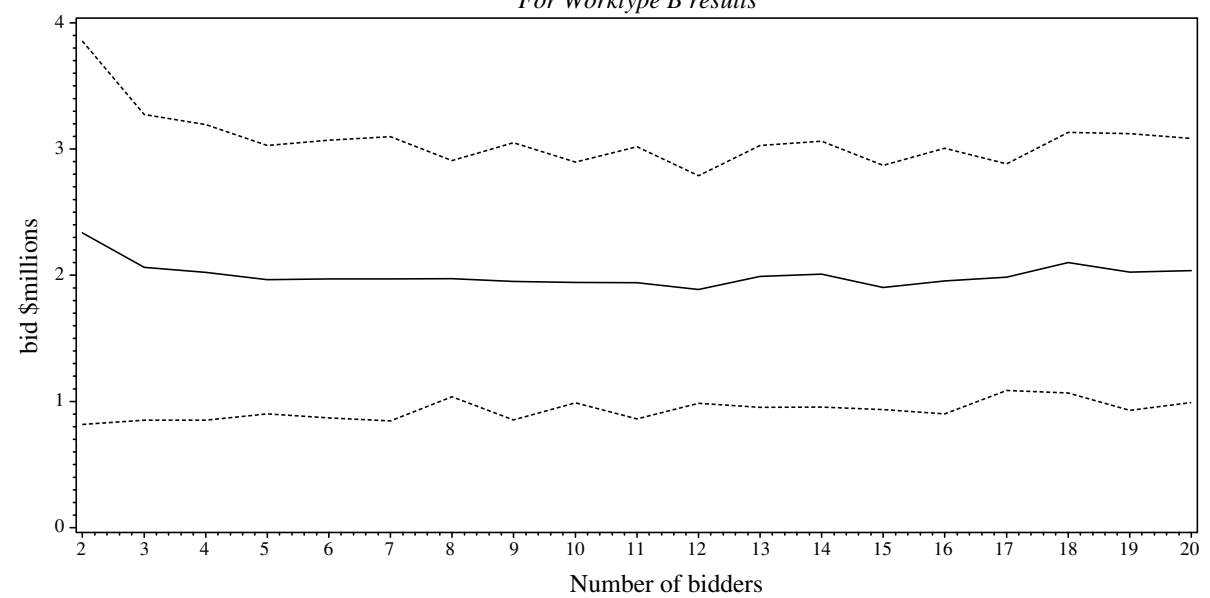

For Worktype C results

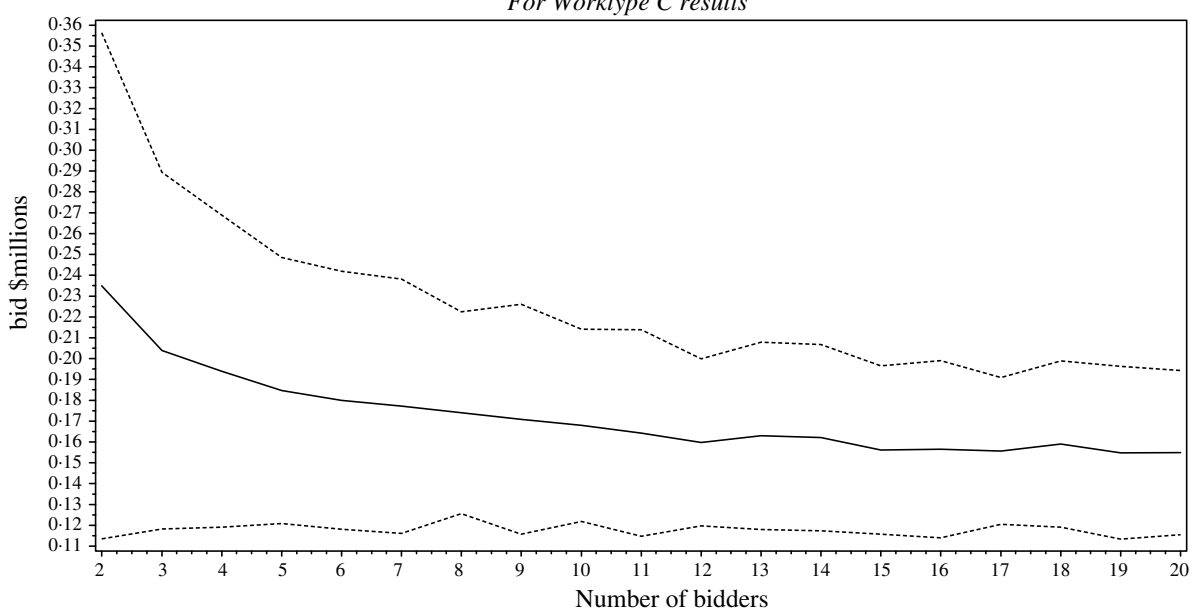

FIGURE 4

Do procurement costs increase in the number of bidders? Legend: average winning bid in solid line; +2 st. dev. and -2 st. dev. in dashed lines 
bidders are involved, and continues to increase for $n>10$. Furthermore, these simulations indicate that the "optimal" number of participants (which would minimize expected procurement costs) would be three, which is half of six, the mode of the empirical distribution of $n$ for the worktype A auctions (cf. Table 2). Our results suggest that the government could lower expected procurement costs by about $15 \%$ by reducing $n$ from 6 to 3 which, considering the average contract outlay of about $\$ 5$ million, constitute substantial savings.

Opposite results are obtained for the worktypes B and $\mathrm{C}$ results. For the worktype $\mathrm{C}$ results, which indicate a negligible common value component, the average winning bids fall quickly in $n$, from an average bid of $\$ 0.23$ million with 2 bidders to about $\$ 0.18$ million, with 10 bidders. This drop also appears in the worktype B results, but is much less precipitous. For these two types of contracts, then, increasing competition would indeed lower procurement costs, and it is optimal for the government to invite as many tenders as possible.

Some well-known results (cf. Wilson (1977), Milgrom (1979)) exist concerning the limiting behaviour of the winning bid at first-price auctions, as the number of bidders grows large. The simulated winning bids for the worktype A auctions indicate that, for the range of $n$ which we observe in the data, the average winning bid is increasing at smaller values of $n$. This does not contradict the theoretical results on information aggregation since that literature has remained silent about whether the (non-stochastic) sequence of average winning bids converges monotonically, at the given parameter values. ${ }^{36}$

\section{CONCLUSIONS}

We empirically measure the effects of the winner's curse on equilibrium bidding in procurement auctions. First, we have estimated a model which allows bidders' latent valuations for a contract to have both common-value and private-value components. To our knowledge, this is the first empirical implementation of a model with such flexible bidder preferences, and represents a methodological contribution of this paper.

Second, we estimate our model on a data set of construction procurement auctions run by the NJDOT in the years 1989-1997. Winning bid simulations performed using our parameter estimates indicate that the average procurement cost in a subset of these auctions is strictly increasing in the number of bidders as competition intensifies: for example, the median costs rise about $15 \%$, as the number of bidders increases from three to six. These results emphasize how asymmetric information can overturn the conventional economic wisdom that more competition is always desirable.

While these results are robust to our attempts to control for across-contract heterogeneity, we recognize that one weakness of our data set is the lack of variables which proxy well for observable contract heterogeneity (such as engineering cost estimates, which have been used in the studies by Bajari (1998) and Jofre-Bonet and Pesendorfer (1999)). It would clearly be of interest to apply the methodology developed in this paper to a data set which contained these variables.

One striking policy implication of our results is that governments may wish to restrict entry, or favour "negotiations" over auctions (cf. Bulow and Klemperer (1996)) when the winner's curse is particularly strong. But in practice, this may not be always feasible, since government procurement agencies try to reduce the possibility of collusion among contractors by inviting more

36. In results which we have not reported, we simulated sequences of winning bids for all three worktypes, and found that while convergence obtains for B and $\mathrm{C}$ type contracts, the sequence of winning bids for worktype A contracts appears to diverge. 
tenders (i.e. increasing competition). ${ }^{37}$ Our findings, while not directly addressing these issues, do contain a striking implication: in situations where the winner's curse is so severe as to lead to higher procurement costs as the number of bidders increases (as in the worktype A results in Figure 4), municipal authorities may actually prefer to allow collusion, since in a common-value setting the informational pooling that arises from bidder discussions may defuse the winner's curse effects. This is one potential justification for why the U.S. government allowed joint bidding in the outer continential shelf offshore lease auctions from their inception in the 1950's until the mid-1970's (cf. Hendricks and Porter (1992, 1996)). The potential benefits of such restrictions on competition have been noted previously in the theoretical literature by, among others, Bulow and Klemperer (1999), and we leave a more thorough analysis to future research.

\section{APPENDIX A. DETAILS ON ESTIMATION}

\section{A.1. Simulation details}

For the Wilson log-normal specification, $E\left(c_{i} \mid x_{1}, \ldots, x_{n}\right)$ can be expressed in analytic form. Before deriving this, we introduce some notation. In this model, the vector $\left(\tilde{c}_{1}=\log c_{1}, \ldots, \tilde{c}_{n}=\log c_{n}, \tilde{x}_{1}=\log x_{1}, \ldots, \tilde{x}_{n}=\right.$ $\left.\log x_{n}\right)$ is distributed jointly normal with identical means $\mu$ for all elements and variance-covariance matrix $\hat{\Sigma}=$ $\left(\left(\Sigma, \Sigma_{12}\right),\left(\Sigma_{12}^{\prime}, \Sigma^{*}\right)\right)^{\prime}$. Furthermore, given the log-normality assumptions, the conditional expectation functions for $c_{i}$ are:

$$
E\left[c_{i} \mid x_{1}, \ldots, x_{n}\right]=\exp \left[E\left(\tilde{c}_{i} \mid \tilde{x}_{1}, \ldots, \tilde{x}_{n}\right)+\frac{1}{2} \operatorname{Var}\left(\tilde{c}_{i} \mid \tilde{x}_{1}, \ldots, \tilde{x}_{n}\right)\right], \quad i=1, \ldots, n .
$$

Next, we denote the marginal variance-covariance matrix of $\left(\tilde{c}_{i}, \tilde{x}_{1}, \ldots, \tilde{x}_{n}\right)$ by

$$
\Sigma_{i} \equiv\left(\begin{array}{cc}
\sigma_{c}^{2} & \sigma_{c}^{* \prime} \\
\sigma_{c}^{*} & \Sigma^{*}
\end{array}\right)
$$

where $\sigma_{c}^{2}=\sigma_{v}^{2}+\sigma_{a}^{2}$ is the variance of $c_{i}$. Using the normality assumption

$$
\begin{aligned}
E\left(\tilde{c}_{i} \mid \tilde{x}\right) & =\mu+\sigma_{c}^{*} \Sigma^{*-1}(\tilde{x}-\mu), \\
\operatorname{Var}\left(\tilde{c}_{i} \mid \tilde{x}\right) & =\sigma_{c}^{2}-\sigma_{c}^{* \prime} \Sigma^{*-1} \sigma_{c}^{*} .
\end{aligned}
$$

Combining expressions (A.2) with equation (A.1), given parameter estimates, the conditional expectation (A.1) can be explicitly evaluated for every vector of $\log$-signals $\left(\tilde{x}_{1}, \ldots, \tilde{x}_{n}\right)$. Consequently, the desired conditional expectations can be obtained by simulation.

Given the analytic expressions for the conditional expectations (A.1), the next step is to calculate the conditional expectations $v(x, x)$. Recall that the vector of $\log$-signals $\left(\tilde{x}_{1}, \ldots, \tilde{x}_{n}\right)$ is jointly normal with mean vector $M^{*}=$ $(\mu, \ldots, \mu)$ and variance-covariance matrix $\Sigma^{*}$. Let $\tilde{x}_{3+}$ denote the sub-vector of log-signals $\tilde{x}_{3}, \ldots, \tilde{x}_{n}$, and $\tilde{x}_{+2}$ denote the vector of log-signals $\tilde{x}_{1}, \tilde{x}_{2}$. Then

$$
\left(\begin{array}{c}
\tilde{x}_{3+} \\
\tilde{x}_{+2}
\end{array}\right) \sim \text { normal }\left(\left[\begin{array}{l}
\mu \\
\mu
\end{array}\right],\left[\begin{array}{cc}
\Sigma_{3+}^{*} & \Sigma_{3+,+2}^{*^{\prime}} \\
\Sigma_{3+,+2}^{*} & \Sigma_{+2}^{*}
\end{array}\right]\right)
$$

where the elements of the mean vector and variance-covariance matrix can be determined from the information structure of the model.

Then, again using the multivariate normal conditional expectation formulas:

$$
\tilde{x}_{3+} \mid \tilde{x}_{+2} \sim \operatorname{normal}\left(\mu+\Sigma_{3+,+2}^{*} \Sigma_{+2}^{*-1}\left(\tilde{x}_{+2}-\mu\right), \Sigma_{3+}^{*}-\Sigma_{3+,+2}^{*} \Sigma_{+2}^{*-1} \Sigma_{3+,+2}^{*}\right) .
$$

Thus, given log-signals $\left(\tilde{x}_{1}, \tilde{x}_{2}\right)$, we can take $S$ draws of $\tilde{x}_{3+}$ according to the conditional distribution (A.3) and simulate the conditional expectation $v(x, x)$. In the results below, we utilized the GHK algorithm for drawing from truncated multivariate distributions. Essentially, this algorithm "importance samples" recursively from the truncated region, one dimension at a time, and allows for smooth (in $\theta$ ) simulation of the required conditional expectation $v_{n}(x, x ; \theta)$.

37. For example, a recent tender of auto-towing contracts in Toronto was scrapped due to low levels of participation while municipal staff were "instructed [...] to come back with suggestions on how more companies might be able to participate" (Toronto Star, 1999). In general, collusion and bid-rigging seem rampant in procurement settings, for example, Pesendorfer (2000), Baldwin, Marshall and Richard (1997) and Porter and Zona (1993) for studies of several instances. 


\section{A.2. Asymptotic distribution for quantile estimator}

Pakes and Pollard (1989) derive a general asymptotic theory for estimators obtained by maximizing simulated objective functions. We utilize expressions for the variance-covariance matrices of the estimators which assume that the number of simulation draws used to calculate the $v_{n}(\cdots ; \theta)$ function increase faster than $\sqrt{T}$, the rate at which $\hat{\theta}$ converges to the true $\hat{\theta}_{0}$.

In what follows, we assume that $\theta$ is $L$-dimensional. For the objective function given in equation (4) in the main text, the following approximate first-order condition characterizes the simulated quantile $(S Q)$ estimator $\hat{\theta} S Q$ :

$$
\frac{1}{\sqrt{T}} \sum_{i=1}^{T} \sum_{j=1}^{n_{i}} \sum_{k=1}^{K}\left\{\tau_{k}-1\left[b_{i j} \leq q_{k}^{n_{i}}\left(\hat{\theta}^{S Q}\right)\right]\right\} \frac{\partial q_{k}^{n_{i}}\left(\hat{\theta}^{S Q}\right)}{\partial \theta}=o_{p}(1) .
$$

It can be shown (cf. Gourieroux and Monfort (1995, Section 8.5.2)) that

$$
\sqrt{T}\left(\hat{\theta}^{S Q}-\theta\right)=-A_{T}^{-1} B_{T}+o_{p}(1)
$$

where

$$
\begin{aligned}
& B_{T}=\frac{1}{\sqrt{T}} \sum_{i=1}^{T} \sum_{j=1}^{n_{i}} \sum_{k=1}^{K}\left\{\tau_{k}-1\left[b_{i j} \leq q_{k}^{n_{i}}\left(\theta_{0}\right)\right]\right\} \frac{\partial q_{k}^{n_{i}}\left(\theta_{0}\right)}{\partial \theta}, \\
& A_{T}=\frac{1}{T} \sum_{i=1}^{T} \sum_{j=1}^{n_{i}} \sum_{k=1}^{K} f_{\tau_{k}}^{n_{i}}\left[q_{k}^{n_{i}}\left(\theta_{0}\right)\right] \frac{q_{k}^{n_{i}}\left(\theta_{0}\right)}{\partial \theta} \frac{q_{k}^{n_{i}}\left(\theta_{0}\right)^{\prime}}{\partial \theta^{\prime}}
\end{aligned}
$$

where $f_{\tau_{k}}^{n_{i}}$ is the density of the marginal distribution of the random variable $s_{n_{i}}(x ; \theta)$ in a $n_{i}$ bidder auction at the $\tau_{k}$-th quantile, where $x$ denotes the signal.

Via a central-limit theorem (using independence over auctions $i$ ), the $L$-vector $B_{T}$ has a limit distribution $N(0, V)$. Therefore, from equation (A.4), the asymptotic variance-covariance matrix for $\hat{\theta}^{S Q}$ can be approximated by

$$
\frac{1}{T} \hat{A}_{T}^{-1} \hat{V}_{T} \hat{A}_{T}^{-1}
$$

$\hat{V}_{T}$ denotes a consistent estimator of $V$, which can be

$$
\hat{V}_{T}=\frac{1}{T} \sum_{i=1}^{T} \hat{m}_{i}\left(b_{i}\right) \hat{m}_{i}\left(b_{i}\right)^{\prime}
$$

where

$$
\hat{m}_{i}\left(b_{i}\right)=\sum_{k=1}^{K} \sum_{j=1}^{n_{i}}\left(\tau_{k}-1\left(b_{i j} \leq q_{k}^{n_{i}}\left(\hat{\theta}^{S Q}\right)\right)\right) \frac{\partial q_{k}^{n_{i}}\left(\hat{\theta}^{S Q}\right)}{\partial \theta} .
$$

The gradient vector $\frac{\partial q_{k}^{n_{i}}\left(\hat{\theta}^{S} Q\right)}{\partial \theta}$, as well as the density $f_{\tau_{k}}^{n_{i}}(\cdot)$ and the gradient $\frac{q_{k}^{n_{i}}\left(\theta_{0}\right)}{\partial \theta}$ in the expression for $A_{T}$ can all be evaluated using finite difference methods.

\section{APPENDIX B. ADDITIONAL SPECIFICATIONS}

\section{B.1. Robustness check 3: potential competition vs. actual competition}

Next we consider a model which allows for the possibility that $N$, the number of actual bidders observed in the data, does not equal $\mathcal{N}$, the number of potential bidders. We present a model where the difference between $\mathcal{N}$ and $N$ arises from a reserve price $r$, which we assume to be constant across all auctions (and is a parameter to be estimated) ${ }^{38}$

We utilize a model of equilibrium bidding in first-price auctions with a reserve price, as in Milgrom and Weber (1982, Section 7). Define the screening value

$$
x_{n}^{*}(r)=\sup \left\{x \mid E\left[V_{1} \mid X_{1}=x, Y_{1}>x\right] \leq r\right\}
$$

38. As noted above, there was no explicit reserve price in these auctions. However, in the model proposed in this section, we rely on an implicit reserve price to generate differences between the potential and actual number of bidders. Note that, without a reserve price, there is no reason in our model why all qualified bidders would not participate in each and every auction (we do not consider capacity constraints or other intertemporal linkages in this analysis). Furthermore, entry or bid preparation costs would not discourage entry in our low-bid auctions (as they do in the high-bid auctions considered in Hendricks et al. (2000) or Milgrom and Weber (1982, Section 7)); they would simply lead bidders to "pad" their bids by the amount of the entry costs. 
where we have subscripted by $n$, the number of bidders. Note that the R.H.S. of this expression is a "participation constraint" which defines the highest participating signal.

Note that the entry cost does not affect the differential equation (1) at all, but changes the boundary conditions to $b^{*}\left(x_{n}^{*}(r)\right)=r$. Therefore, the equilibrium bid function becomes

$$
b_{n}^{*}(x ; r) \begin{cases}=L_{n}\left(x, x_{n}^{*}(r)\right) * r+\int_{x}^{x_{n}^{*}(r)} v_{n}(\alpha, \alpha) d L_{n}(x, \alpha) & \text { if } x<x_{n}^{*}(r) \\ >r & \text { otherwise }\end{cases}
$$

where

$$
L_{n}(x, y)=\exp \left(-\int_{x}^{y} \frac{f_{-1, n}(s \mid s)}{1-F_{-1, n}(s \mid s)} d s\right)
$$

Note that $L(x, x)=1$.

Integrating by parts, we derive a simpler expression

$$
b_{n}^{*}(x ; r) \begin{cases}=\left(r-v_{n}\left(x_{n}^{*}(r), x_{n}^{*}(r)\right)\right) * L_{n}\left(x, x_{n}^{*}(r)\right)+v_{n}(x, x)+\int_{x}^{x_{n}^{*}(r)} L_{n}(x, \alpha) v_{n}^{\prime}(\alpha, \alpha) d \alpha & \text { if } x<x_{n}^{*}(r) \\ >r & \text { otherwise. }\end{cases}
$$

We need an estimate of $r$ in order to simulate the equilibrium bid function. Assuming that $r$ is constant across all auctions of a given worktype, a natural estimate of $r$ is $\max _{i, j} b_{i j}$, the highest bid observed in the data. As is well known (cf. Donald and Paarsch $(1993,1996)$ ), this estimate is superconsistent, and its estimation does not affect the asymptotic distribution of our $S Q$ estimator. Given $r$, we compute the screening values $x_{n}^{*}(r)$ for $n=1,2, \ldots$ via the implicit relation (B.1). Given these screening values, we compute the equilibrium bid function (B.2).

Furthermore, given our parametric assumption and the parameter values, we can calculate the probability that $N$ out of the $\mathcal{N}$ potential bidders submit bids (see Paarsch (1997) for a derivation of this result):

$$
\begin{aligned}
& P_{N, \mathcal{N}} \equiv \operatorname{Binomial}\left(N, \mathcal{N}, \Phi\left(\log x_{\mathcal{N}}^{*}(r)\right)\right)
\end{aligned}
$$

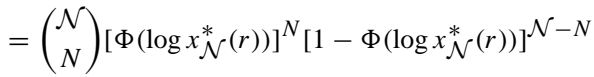

where $\Phi(\cdot)$ denotes the marginal CDF of the log-signals.

Since $\mathcal{N}$ is unobserved by the econometrician, we treat it as a random variable which, conditional on the observed number of bidders $N$, we assume to follow a multinomial probability law:

$$
\operatorname{Pr}(\mathcal{N} \mid N)=\frac{P_{N, \mathcal{N}}}{\sum_{\mathcal{N}^{\prime}=N}^{N+5} P_{N, \mathcal{N}^{\prime}}}, \quad \mathcal{N}=N, N+1, \ldots, N+5
$$

For an auction with $N$ observed bidders, we simulated bids by drawing an $\mathcal{N}$ according to (B.4), and then calculating the equilibrium bid corresponding to this $\mathcal{N}$ using the top equation in (B.2) above. The results from these specifications are given in Table B1. The magnitudes of the important $\sigma$ parameters do not differ greatly from the random effect estimates from Table 5, and for that reason we will not discuss them further.

\section{B.2. Robustness check 4: accounting for contract-specific heterogeneity}

In the final robustness check, we control for observed heterogeneity across contracts by parameterizing $\mu_{i}$, the median of the signal distribution for auction $i$, as a function not only of $n_{i}$, the number of bidders in auction $i$, but also the covariates specific to auction $i$. The two most important dimensions of heterogeneity are size differences across contracts of a given worktype, and changes in input costs across time which also exogenously affect bids for a contract. Since our bid data do not allow us to determine the per-unit costs submitted by the bidders, adequately controlling for size heterogeneity is particularly important.

We were only able to obtain contract-specific covariates for the worktype A contracts. This is because many of these contracts specified roads upon which work was to be done. We obtained contract-specific covariates which were characteristics of these roads, as extracted from a database maintained by the NJDOT. They are: TRAFFIC, a measure of the weekday traffic volume (in both directions) of the road being repaired; and geographic dummies (GATEWAY, SKYLANDS, SHORE, DELAWARE, SOUTH) which describe the geographic location of the road. Furthermore, we also obtained construction cost indices corresponding to the month in which a particular contract was auctioned from the trade publication Engineering News-Record (NY is the index for New York City, and PHIL is the index for Philadelphia; in our specification, we use an average of the two). Table B2 summarizes the covariates. 
TABLE B1

Parameter estimates. Robustness check 3: potential competition vs. actual competition. Standard errors in parentheses

\begin{tabular}{|c|c|c|c|}
\hline $\begin{array}{l}\text { Worktype: } \\
\text { Parameter }\end{array}$ & A & B & $\mathrm{C}$ \\
\hline$\sigma_{v}$ & $0.9625(0.0002)$ & $0.0995(0.0003)$ & $0.0133(0.0002)$ \\
\hline$\sigma_{a}$ & $2.5029(0.0072)$ & $0 \cdot 2115(0 \cdot 0010)$ & $0.6319(0.0013)$ \\
\hline$\sigma_{e}$ & $1.3393(0 \cdot 0020)$ & $0.6618(0 \cdot 0003)$ & $0.1538(0.0010)$ \\
\hline$\eta_{1}$ & $-2.5979(0.0098)$ & $2.0491(0.0078)$ & $-1.9606(0.0050)$ \\
\hline$\eta_{2}$ & $-1.7019(0.0098)$ & $1.3089(0.0073)$ & $-1 \cdot 2616(0 \cdot 0028)$ \\
\hline$\eta_{3}$ & $-1.2705(0.0102)$ & $0.9913(0.0072)$ & $-0.9659(0.0015)$ \\
\hline$\eta_{4}$ & $-0 \cdot 8501(0 \cdot 0109)$ & $0.7086(0.0072)$ & $-0.7060(0.0007)$ \\
\hline$\eta_{5}$ & $-0.4407(0.0118)$ & $0.4608(0.0073)$ & $-0.4820(0 \cdot 0022)$ \\
\hline$\eta_{6}$ & $-0.0424(0.0129)$ & $0.2480(0.0074)$ & $-0.2939(0.0042)$ \\
\hline$\eta_{7}$ & $0.3448(0.0142)$ & $0.0702(0.0076)$ & $-0.1416(0.0064)$ \\
\hline$\eta_{8}$ & $0.7210(0.0155)$ & $-0.0728(0.0079)$ & $-0.0251(0.0089)$ \\
\hline$\eta_{9}$ & $1.0862(0.0170)$ & $-0 \cdot 1807(0.0083)$ & $0.0555(0.0115)$ \\
\hline$\eta_{10}$ & $1.4403(0.0186)$ & $-0.2537(0.0088)$ & $0.1002(0.0144)$ \\
\hline$\eta_{11}$ & $1.7834(0.0202)$ & $-0.2918(0.0093)$ & $0 \cdot 1091(0 \cdot 0174)$ \\
\hline$\eta_{12}$ & $2.1154(0.0219)$ & $-0.2949(0.0099)$ & $0.0821(0.0207)$ \\
\hline$\eta_{13}$ & $2.4363(0.0237)$ & $-0.2630(0.0106)$ & $0.0193(0.0241)$ \\
\hline$\eta_{14}$ & $2 \cdot 7463(0 \cdot 0256)$ & $-0 \cdot 1963(0 \cdot 0114)$ & $-0.0794(0.0278)$ \\
\hline$\eta_{15}$ & $3 \cdot 0451(0.0274)$ & $-0.0945(0.0123)$ & $-0.2139(0.0317)$ \\
\hline$\sigma_{\eta_{1}}$ & $0.4314(0.0019)$ & $0 \cdot 3403(0 \cdot 0004)$ & $0.7867(0.0007)$ \\
\hline$\sigma_{\eta_{2}}$ & $0.4314(0.0019)$ & $0.3403(0 \cdot 0004)$ & $0.7867(0.0007)$ \\
\hline$\sigma_{\eta_{3}}$ & $0.4648(0.0021)$ & $0.3468(0.0004)$ & $0.7689(0.0006)$ \\
\hline$\sigma_{\eta_{4}}$ & $0.5017(0.0024)$ & $0 \cdot 3575(0 \cdot 0004)$ & $0.7506(0.0006)$ \\
\hline$\sigma_{\eta_{5}}$ & $0.5424(0.0027)$ & $0.3727(0.0004)$ & $0.7317(0.0006)$ \\
\hline$\sigma_{\eta_{6}}$ & $0.5875(0.0031)$ & $0.3929(0.0005)$ & $0.7125(0.0006)$ \\
\hline$\sigma_{\eta_{7}}$ & $0.6374(0.0035)$ & $0.4190(0.0005)$ & $0.6929(0.0006)$ \\
\hline$\sigma_{\eta_{8}}$ & $0.6928(0.0041)$ & $0.4519(0.0006)$ & $0.6730(0.0007)$ \\
\hline$\sigma_{\eta_{9}}$ & $0.7543(0.0047)$ & $0.4929(0.0007)$ & $0.6529(0.0007)$ \\
\hline$\sigma_{\eta_{10}}$ & $0.8227(0.0054)$ & $0.5437(0.0008)$ & $0.6326(0.0007)$ \\
\hline$\sigma_{\eta_{11}}$ & $0.8988(0.0062)$ & $0 \cdot 6066(0 \cdot 0010)$ & $0.6121(0.0007)$ \\
\hline$\sigma_{\eta_{12}}$ & $0.9837(0.0071)$ & $0.6844(0.0012)$ & $0.5916(0.0008)$ \\
\hline$\sigma_{\eta_{13}}$ & $1.0785(0.0082)$ & $0.7810(0.0015)$ & $0.5710(0.0008)$ \\
\hline$\sigma_{\eta_{14}}^{\eta_{113}}$ & $1.1845(0.0095)$ & $0.9014(0.0019)$ & $0.5505(0.0009)$ \\
\hline$\sigma_{\eta_{15}}$ & $1 \cdot 3031(0 \cdot 0109)$ & $1.0521(0.0025)$ & $0.5301(0.0009)$ \\
\hline Simulation draws: ${ }^{a}$ & 50 & 50 & 50 \\
\hline
\end{tabular}

${ }^{a}$ Number of simulation draws used in calculating $v_{n}(x, x ; \theta)$.

Using these covariates, we parameterize $\mu_{i}$ as:

$$
\mu_{i}=\mu_{0}+\mu_{1} * n_{i}+\mu_{2} * n_{i}^{2}+\mu_{3} *\left(\frac{1}{2} * \mathrm{NY}+\mathrm{PHIL}\right)+\mu_{4} * \text { TRAFFIC }+\left(\mu_{5} \mu_{6} \mu_{7} \mu_{8} \mu_{9}\right)\left(\begin{array}{c}
\text { GATEWAY } \\
\text { SKYLANDS } \\
\text { SHORE } \\
\text { DELAWARE } \\
\text { SOUTH }
\end{array}\right)
$$

Since we were only able to obtain covariates for the worktype A contracts, this specification was only estimated on those auctions. The results are reported in Table B3. The magnitudes and signs of the parameters common across all the specifications remain quite stable (relative to the random effects specifications in Table 5) to the incorporation of covariates. In particular, note that $\sigma_{e}$, which measures the noisiness of bidders' signals, continues to be large in magnitude $(2.3400$ [0.0072] $)$, which implies that contractors' cost signals are very noisy, which tends to reinforce our finding of a strong winner's curse effect in these auctions (as we discuss below). Furthermore, most of the covariates enter significantly in the specification, and in the direction expected (for example, COST enters positively). Give the stability of the point estimates between the random effects and observed heterogeneity specifications, then, we will not discuss these results further. 


\section{TABLE B2}

Contract-specific covariates: highway-work contracts

\begin{tabular}{|c|c|c|c|c|c|}
\hline Variable & $N$ & Mean & Std. dev. & Minimum & Maximum \\
\hline Total Auctions & 415 & & & & \\
\hline NY & 410 & $7588 \cdot 57$ & $737 \cdot 28$ & $6234 \cdot 50$ & 8967.49 \\
\hline PHIL & 410 & $6005 \cdot 94$ & $521 \cdot 88$ & 5083.90 & $7311 \cdot 37$ \\
\hline TRAFFIC & 364 & $27,996 \cdot 41$ & $21,227 \cdot 55$ & 0 & $97,235 \cdot 00$ \\
\hline GATEWAY & 364 & 0.56 & 0.50 & 0 & 1.00 \\
\hline SKYLANDS & 364 & $0 \cdot 35$ & 0.48 & 0 & 1.00 \\
\hline SHORE & 364 & $0 \cdot 24$ & 0.43 & 0 & 1.00 \\
\hline DELAWARE & 364 & 0.49 & 0.50 & 0 & 1.00 \\
\hline SOUTH & 364 & $0 \cdot 26$ & 0.44 & 0 & 1.00 \\
\hline
\end{tabular}

See text for definitions of variables.

\section{TABLE B3}

Parameter estimates. Robustness check 4: accounting for observed contract heterogeneity. Standard errors in parentheses. Estimated for worktype A contracts only

\begin{tabular}{lc}
\hline Parameter & $0 \cdot 2767(0 \cdot 0014)$ \\
\hline$\sigma_{v}$ & $0.9023(0 \cdot 0004)$ \\
$\sigma_{a}$ & $2 \cdot 3400(0 \cdot 0072)$ \\
$\sigma_{e}$ & $-2 \cdot 0214(0 \cdot 0088)$ \\
$\mu_{0}$ & $0 \cdot 4179(0 \cdot 0072)$ \\
$\mu_{1}$ & $-0 \cdot 0545(0 \cdot 0015)$ \\
$\mu_{2}$ & $3 \cdot 469 \mathrm{E}-5(1 \cdot 761 \mathrm{E}-7)$ \\
$\mathrm{COST}^{a}\left(\mu_{3}\right)$ & $-4 \cdot 856 \mathrm{E}-7(2 \cdot 331 \mathrm{E}-9)$ \\
TRAFFIC $\left(\mu_{4}\right)$ & $0 \cdot 0616(2 \cdot 399 \mathrm{E}-4)$ \\
GATEWAY $\left(\mu_{5}\right)$ & $0 \cdot 0760(7 \cdot 369 \mathrm{E}-4)$ \\
SKYLANDS $\left(\mu_{6}\right)$ & $-0 \cdot 0062(4.424 \mathrm{E}-5)$ \\
SHORE $\left(\mu_{7}\right)$ & $-0 \cdot 0190(6 \cdot 495 \mathrm{E}-5)$ \\
DELAWARE $\left(\mu_{8}\right)$ & $0 \cdot 1479(5 \cdot 694 \mathrm{E}-4)$ \\
SOUTH $\left(\mu_{9}\right)$ & 356 \\
\# contracts & 50 \\
Simulation draws ${ }^{b}$ & \\
\hline
\end{tabular}

$a$ See text for definitions of covariates. COST $=$ $\frac{1}{2}(\mathrm{NY}+\mathrm{PHIL})$.

$b$ Number of simulation draws used in calculating $v_{n}(x, x ; \theta)$.

Acknowledgements. The authors thank Marty Miller at the NJDOT for providing us with the data, and patiently answering our questions. We thank Jason Cummins, Mike Peters, David Sappington and Aloysius Siow as well as seminar participants at Carnegie-Mellon, the Einaudi Foundation (Rome), Florida, Johns Hopkins, Harvard, NYU, Queen's, Rochester, Stanford, UCL, Yale, and the 1999 NASM (Madison, Wisconsin) for comments. Hai Che provided research assistance. We gratefully acknowledge financial assistance from the National Science Foundations (Hong: SES 0079495; Shum: SES 0003352) and from SSHRC. We thank the associate editor and two referees for extensive comments.

\section{REFERENCES}

ANDREWS, D. (1998), "Hypothesis Testing with a Restricted Parameter Space”, Journal of Econometrics, 86, $155-199$. ARMSTRONG, M. (1996), "Multiproduct Nonlinear Pricing", Econometrica, 64, 51-75.

BAJARI, P. (1998), "A Structural Econometric Model of the First Price Sealed Bid Auction: with Applications to Procurement of Highway Improvements"(Mimeo, Stanford University).

BAJARI, P. and HORTACSU, A. (1999), "Winner's Curse, Reserve Prices, and Endogenous Entry: Empirical Insights from eBay Auctions"(Mimeo, Stanford University). 
BALDWIN, L., MARSHALL, R. and RICHARD, J.-F. (1997), "Bidder Collusion at Forest Service Timber Sales", Journal of Political Economy, 105, 657-699.

BORDLEY, R. and HARSTAD, R. (1996), "Lottery Qualification Auctions", in M. Baye (ed.) Advances in Applied Microeconomics, Vol. 6 (Auctions) (JAI Press, Inc.).

BULOW, J. and KLEMPERER, P. (1996), “Auctions vs Negotiations”, American Economic Review, 86, $180-194$.

BULOW, J. and KLEMPERER, P. (1999), "Prices and the Winner's Curse"(Mimeo, Oxford University).

DELTAS, G. and CHAKRABORTY, I. (1997), "A Two-stage Approach to Structural Econometric Analysis of First-price Auctions"(Mimeo, University of Illinois).

DONALD, S. and PAARSCH, H. (1993), "Piecewise Pseudo-Maximum Likelihood Estimation in Empirical Models of Auctions", International Economic Review, 34, 121-148.

DONALD, S. and PAARSCH, H. (1996), "Identification, Estimation, and Testing in Parametric Empirical Models of Auctions within the Independent Private Values Paradigm", Econometric Theory, 12, 517-567.

GOURIEROUX, C. and MONFORT, A. (1995) Statistics and Econometric Models, Vol. 1, translated from the French by Q. Vuong (Cambridge: Cambridge University Press).

GUERRE, E., PERRIGNE, I. and VUONG, Q. (2000), "Optimal Nonparametric Estimation of First-price Auctions”, Econometrica, 68, 525-574.

HAILE, P., HONG, H. and SHUM, M. (2000), "A Nonparametric Test for Common Values" (Mimeo, University of Wisconsin).

HALPIN, D. and WOODHEAD, R. (1998) Construction Management, 2nd edition (New York: John Wiley and Sons).

HECKMAN, J. and SINGER, B. (1984), "A Method for Minimizing the Impact of Distributional Assumptions in Econometric Models for Duration Data", Econometrica, 52, 271-320.

HENDRICKS, K., PINKSE, J. and PORTER, R. (2000), "Empirical Implications of Equilibrium Bidding in First-price, Symmetric, Common-value Auctions"(Mimeo, University of British Columbia).

HENDRICKS, K. and PORTER, R. (1992), “Joint Bidding in Federal OCS Auctions”, American Economic Review, 82, 506-511.

HENDRICKS, K. and PORTER, R. (1996), "Joint Bidding and Entry in Federal Offshore Oil and Gas Lease Auctions" (Mimeo, University of British Columbia).

HONG, H. and SHUM, M. (2000), "Econometric Models of Asymmetric Ascending Auctions" (Mimeo, Princeton University).

JOFRE-BONET, M. and PESENDORFER, M. (1999), "Bidding Behavior in a Repeated Procurement Auction"(Mimeo, Yale University).

KAGEL, J. and LEVIN, D. (1986), “The Winner's Curse and Public Information in Common Value Auctions”, American Economic Review, 76, 894-920.

KRISHNA, V. and MORGAN, J. (1997), “(Anti-) Competitive Effects of Joint Bidding and Bidder Restrictions”(Mimeo, Penn State).

LAFFONT, J. J., OSSARD, H. and VUONG, Q. (1995), "Econometrics of First-price Auctions", Econometrica, 63, 953-980.

LAFFONT, J. J. and VUONG, Q. (1996), "Structural Analysis of Auction Data", American Economic Review, Papers and Proceedings, 86, 414-420.

LI, T., PERRIGNE, I. and VUONG, Q. (2000), "Conditionally Independent Private Information in OCS Wildcat Auctions", Journal of Econometrics, 98, 129-161.

MANSKI, C. (1994), "Analog Estimation of Econometric Models", in R. Engle and D. McFadden (eds.) Handbook of Econometrics, Vol. 4 (Amsterdam: North-Holland).

MATTHEWS, S. (1984), "Information Acquisition in Discriminatory Auctions", in M. Boyer and R. Kihlstrom (eds.) Bayesian Models in Economic Theory (North-Holland).

MCAFEE, P. and MCMILLAN, J. (1987) Incentives in Government Contracting (University of Toronto Press).

MILGROM, P. (1979), "A Convergence Theorem for Competitive Bidding with Differential Information", Econometrica, 47, 679-688.

MILGROM, P. (1982), "Good News and Bad News: Representation Theorems and Applications”, The Bell Journal of Economics, 13, 380-391.

MILGROM, P. and WEBER, R. (1982), “A Theory of Auctions and Competitive Bidding”, Econometrica, 50, 1089-1122.

MILGROM, P. and WEBER, R. (1985), "Distributional Strategies for Games with Incomplete Information”, Mathematics of Operations Research, 10, 619-632.

PAARSCH, H. (1992), "Deciding Between the Common and Private Value Paradigms in Empirical Models of Auctions", Journal of Econometrics, 51, 191-215.

PAARSCH, H. (1997), "Deriving an Estimate of the Optimal Reserve Price: an Application to British Columbian Timber Sales", Journal of Econometrics, 78, 333-357.

PAKES, A. and POLLARD, D. (1989), "Simulation and the Asymptotics of Optimization Estimators", Econometrica, 57, 1027-1057.

PESENDORFER, M. (2000), "A Study of Collusion in First-price Auctions”, Review of Economic Studies, 67, $390-412$.

PESENDORFER, W. and SWINKELS, J. (2000), "Efficiency and Information Aggregation in Auctions", American Economic Review, 90, 499-525.

PINKSE, J. and TAN, G. (2000), "Fewer Bidders Can Increase Price in First-price Auctions with Affiliated Private Values"(Mimeo, University of British Columbia).

PORTER, R. and ZONA, D. (1993), "Detection of Bid Rigging in Procurement Auctions", Journal of Political Economy, 101, 518-538. 
POWELL, J. (1984), "Least Absolute Deviations Estimation for the Censored Regression Model", Journal of Econometrics, 25, 303-325.

ROCHET, J. and STOLE, L. (2000), “The Economics of Multidimensional Screening”(Mimeo, University of Toulouse). SMILEY, A. (1979) Competitive Bidding Under Uncertainty: the Case of Offshore Oil (Ballinger Publishing Company). THIEL, S. (1988), "Some Evidence on the Winner's Curse”, American Economic Review, 78, 884-895.

VARIAN, H. (1992) Microeconomic Analysis (Norton).

WILSON, R. (1977), “A Bidding Model of Perfect Competition”, Review of Economic Studies, 44, 511-518.

WILSON, R. (1983), "On Competitive Bidding Applied”, in R. Englebrecht-Wiggans, R. Stark and M. Shubik (eds.) Auctions, Bidding and Contracting: Uses and Theory (Academic Press).

WILSON, R. (1998), "Sequential Equilibria of Asymmetric Ascending Auctions", Economic Theory, 12, $433-440$.

WOLAK, F. (1989), "Local and Global Testing of Linear and Nonlinear Inequality Constraints in Nonlinear Econometric Models", Econometric Theory, 1, 1-35. 